\title{
The Tied Migrant Employment Penalty: Public Perceptions of Military Spouses Seeking Work
}

\author{
Brittany N. Dernberger \\ Department of Sociology \\ University of Maryland
}

May 12, 2017

WORKING PAPER

Contact information: Brittany N. Dernberger, Department of Sociology, University of Maryland, 2112 Parren Mitchell Art-Sociology Building, 3834 Campus Drive, College Park, Maryland, 20742, bdernber@terpmail.umd.edu.

Acknowledgements: Thank you to Meredith Kleykamp for invaluable feedback and guidance on this project. I also thank Philip Cohen and Mary DeStefano for helpful suggestions and insight. 


\begin{abstract}
People who move to support the employment prospects of their spouses are tied migrants, and military spouses experience tied migration repeatedly: active duty military personnel move about once every two years, twice as often as civilian families. This frequent geographical disruption directly affects the career trajectories of military spouses. Previous research established military spouses experience worse employment outcomes than their civilian peers, but less is known about the specific characteristics that lead to this difference. Do military spouses have worse employment outcomes because of being a tied migrant, or is there a separate effect because of their status as a military spouse?

This article analyzes original data from a factorial vignette survey in which respondents evaluated fictitious job applicant profiles. Results suggest (1) Military spouses receive a premium as job applicants, they are evaluated as more warm, competent, reliable, and social, but receive lower evaluations on perceived longevity; (2) Military spouses with a stable geographic history are evaluated higher than civilians, but that premium switches to a penalty for military spouses with a history of moving frequently, in which case they are evaluated more harshly than civilians who have moved frequently; and (3) Neither tied migration nor military spouse status influence starting salary offers. As many careers require employees to move as part of their training or to seek advancement opportunities, understanding the employment-related challenges and opportunities military spouses face can lead to implications that may affect other tied migrants.
\end{abstract}




\section{INTRODUCTION}

Relocating to a new community can be stressful and disruptive, and this strain may be compounded if the reason for moving is not personal, but instead for the benefit of a partner or family member. People who move to support the employment prospects of their partners or spouse are tied migrants (Mincer 1978). Those married to someone in the military experience

tied migration repeatedly, as active duty military personnel move about once every two to three years (Bradbard, Maury, and Armstrong 2016). This is more than twice as often as civilian families, and has direct implications for the 1.8 million active duty military spouses and more than 15 million military veterans' spouses in the United States (Bradbard et al. 2016). In particular, these frequent moves, which serve the needs of the military as an institution, directly impact children who relocate to new schools and spouses who must leave jobs (Segal 1986). By virtue of being married to someone in the military, military spouses face a number of employment challenges. Unemployment rates for military spouses are triple those of their civilian peers, they face an earnings penalty of approximately $38 \%$ compared to their civilian counterparts, and experience high rates of underemployment based on their educational and employment backgrounds (Bradbard et al. 2016; Castaneda and Harrell 2007; Hosek and Wadsworth 2013). The military isn't the only career requiring frequent relocations for training or for advancement opportunities; the medical profession, academia, and corporate managers are among many fields that often involve relocations. One survey found that of those who had moved in the prior year, almost half (44\%) moved for a job or business opportunity (Taylor et al. 2008). Thus, understanding the employment-related challenges and opportunities military spouses face can lead to implications that may affect other tied migrants. 
While previous research has established employment discrepancies among military spouses, such as higher rates of underemployment, unemployment, and lower wages, less is known about the specific characteristics, or combination of characteristics, that lead to this difference. Do military spouses have worse employment outcomes because of being a tied migrant, or is there a separate effect because of their status as a military spouse? Specifically, how are these differences perceived by others, especially prospective employers? This study seeks to understand how the employment prospects of military spouses are affected by the frequent geographical moves required by the military, distinguishing the effect of an interrupted work history from the status of being a military spouse as influences on evaluations as prospective job candidates. This study examines how members of the public, and the subset who have hiring experience, evaluate job applicants using an original factorial vignette survey and comparing evaluations of military and civilian spouses with stable versus interruped work histories. In brief, I find (1) Regardless of whether military spouses have actually moved frequently in the past or not, they are rated lower than comparable civilian spouses on anticipated job tenure (longevity) with a company; (2) Military spouses with a stable geographic history are evaluated higher than civilians, but that premium switches to a penalty for military spouses with a history of moving frequently, in which case they are evaluated more harshly than civilians who have moved frequently; and (3) Neither tied migration nor military spouse status influence starting salary offers. 


\section{THEORETICAL BACKGROUND}

\section{Tied Migration}

Tied migrants are people who move to support the employment prospects of their spouses, such as moving for a new job, promotion, or opportunity (Mincer 1978). This work/family dynamic has become more complicated as women have entered the labor force and many households include two-earner families. Mincer (1978) found that tied migration generally increased employment for men, but increased unemployment for women, as women were often the "tied movers" who moved to support their husbands' career. The gender-specific nature of tied migration is not necessarily a relic of the $20^{\text {th }}$ Century; Shauman and Noonan (2007) found that married women are significantly less likely than married men to experience labor market gains from tied migration. Their results align with Mincer (1978) in that women experienced inconsistent employment and declining earnings, while men experienced a growth in earnings (Shauman and Noonan 2007).

Family-level decisions are further complicated by structural forces, such as the occupational segregation between men and women. From this perspective, the gendered nature of tied migration is attributed to women being more likely to be in flexible occupations, such as health care, education, or administrative jobs that do not require moving (Benson 2014). Benson (2014) finds families are equally likely to relocate for work when the wife has a job that requires moving, but that the gender disparity emerges because of women being less likely to be in these types of positions. The "trailing wife" trope may no longer be representative of all families; rates of tied migration are similar for men and women, although family decisions about moving are still influenced by gender (Cooke 2013; Wong 2017). 
Regardless of the gender of the lead/tied migrant, tied migration leads to interruptions in work (Cooke and Speirs 2005; Cooney, De Angelis, and Segal 2011; Schwartz, Wood, and Griffith 1991). Therefore, I expect job applicants with a history of frequent moving to be evaluated lower than those with a history of geographic stability.

Hypothesis 1A: Applicants with a history of frequent moving (tied migrants) will receive lower hiring recommendations than comparable candidates with a history of geographic stability. Hypothesis 1B: Applicants with a history of frequent moving (tied migrants) will receive lower starting salary offers than comparable candidates with a history of geographic stability.

\section{Employment Challenges for Military Spouses}

Military spouses experience tied migration repeatedly because of the frequent geographical moves required by the military, which leads to severe disruptions in their employment trajectories. Military spouses have lower employment rates, and those who are employed have lower wages, than civilian spouses (Harrell et al. 2004). Furthermore, research indicates that civilians with comparable observed characteristics to military spouses fare better in terms of employment outcomes than both military spouses and the civilian average (Harrell et al. 2004). This indicates military spouses should have better outcomes than the average civilian spouse based on observed characteristics, such as education level, yet they actually have worse employment outcomes (Harrell et al. 2004). Recent estimates suggest military spouses have unemployment rates that are triple those of their civilian peers, an earnings penalty of approximately $38 \%$ compared to their civilian counterparts, and high rates of underemployment based on their educational and employment backgrounds (Bradbard et al. 2016; Castaneda and Harrell 2007; Hosek and Wadsworth 2013). 
Reflecting the increase of women in the military, recent military-specific tied migration literature has compared differences between civilian husbands and wives who are married to someone in the military. For military wives, migration is associated with a $10 \%$ decline in employment and four-hour decline in hours worked per week; for military husbands, migration is associated with $6 \%$ employment decline and a five-hour reduction in hours worked per week (Cooke and Speirs 2005). Similarly, Hisnanick and Little (2015) found that military spouses both men and women - experience a similar earnings gap, although the penalty is a bit sharper for women (43\% for husbands and 53\% for wives). Because of the demonstrated employment challenges military spouses encounter (Bradbard et al. 2016; Castaneda and Harrell 2007; Hosek and Wadsworth 2013), it is expected that military spouses will be evaluated lower than comparable civilian spouses.

Hypothesis 2A: Military spouses will receive lower hiring recommendations than comparable civilian spouses.

Hypothesis $2 B$ : Military spouses will receive lower starting salary offers than comparable civilian spouses.

\section{Military Spouses as Tied Migrants}

Military spouses have worse employment outcomes than their comparable civilian peers. Previous research suggests a host of structural challenges facing military spouses, including frequent moves causing career disruption, the limited labor markets where military bases are generally located (Booth 2003), employer bias and stigma (Castaneda and Harrell 2007; Harrell et al. 2004; United States Goverthenment Accountability Office 2012), and the tension between the "greedy institutions" of the military and family that compete for loyalty, time, and energy of family members (Bourg and Segal 1999: 633). Yet a key question remains in the literature: do 
military spouses have worse employment outcomes because of being a tied migrant, or is there a separate effect because of their status as a military spouse?

From an economic perspective, tied migration should lead to an increase in earnings for the lead migrant, which is why it is a rational decision for a family to move for an employment opportunity (Mincer 1978). However, the move is not necessarily a rational decision for the tied migrant, who often experiences a decrease in earnings when the family relocates (Cooke 2013). From a strict economic perspective, couples would make a joint decision to relocate based on maximizing total household earnings (Mincer 1978), which often means privileging the higher earner. However, this model of decision making does not hold true for military families, who must move based on the military, and the military member - the lead migrant - is not moving to increase his economic opportunities 1 .

The high rate of frequent moving from being a tied migrant, moving based on the needs of their spouse and the military, hinders the accumulation of job experience and firm-specific human capital for military spouses (Belkhir et al. 2011; Castaneda and Harrell 2007; Harrell et al. 2004; Lakhani 1994; Mincer 1978; Payne et al. 1992; Schwartz et al. 1991). Employers may be less likely to invest in the human capital of military spouses (i.e. training, education, and onboarding), out of fear that there will be limited return on this investment due to their anticipated short job tenure (Castaneda and Harrell 2007; Hisnanick and Little 2015; Hosek and Wadsworth 2013). The interaction between tied migration, signaled by frequent moving, and the status of being a military spouse remains an empirical question. If frequent moving is the key determinant of lower employment outcomes, military spouses may fare better than civilian spouses because an interrupted work history can be explained (i.e. moving due to having a

\footnotetext{
${ }^{1}$ Although there may be economic consequences if a service member decides to leave the military.
} 
spouse in the military), while a comparable civilian applicant would not have a socially acceptable explanation. Alternatively, perhaps employers have a bias towards military spouses and evaluate them differently than civilian spouses independent of frequent moving history, leading to disparate hiring outcomes because of the status of being a military spouse. Hypothesis 3A: Military spouses with a history of frequent moving will receive higher hiring recommendations than comparable civilian spouses with a history of frequent moving. Hypothesis $3 B$ : Military spouses with a history of frequent moving will receive higher starting salary offers than comparable civilian spouses with a history of frequent moving.

\section{Employer Hiring Decisions}

While human capital characteristics of workers are important aspects of the hiring process, investigating the role of personnel managers - and their subsequent hiring decisions are also vital to understand how, and why, job candidates are selected (Jones Young and Powell 2015; Park 1999). Making a bad hire can be costly to employers, so hiring decision makers rely on a variety of signals and clues in an attempt to make the best possible hiring decisions with limited information about job candidates. First, employers may use job history data, such as job hopping, periods of unfilled time, absences from work, tardiness to work, wage history, and reasons for leaving past employers to assist employers in evaluating job candidates (Bills 1990). These aspects of an applicant's employment background provide information about reliability

(e.g. Will the employee show up on time each day?) and longevity (e.g. Will the employee leave shortly after finishing training, or will they be with the company over a long period of time?), two key characteristics that signal whether a job candidate will be a good employee.

Secondly, warmth and competence are two specific characteristics employers rely on when making social judgments about prospective employees (Krings, Sczesny, and Kluge 2011). 
Social perception is based on perceived warmth and competence, and these perceptions then generate positive or negative emotions (Cuddy, Fiske, and Glick 2008). For instance, in a study about age discrimination, Krings et al. (2011) found older workers were perceived as warm, but less competent, than younger workers. Even if jobs required mostly warmth-related qualities, older candidates were discriminated against, indicating perceptions of competence and warmth are key qualities employers evaluate when making hiring decisions (Krings et al. 2011).

Finally, in addition to formal credentials and technical skills, employers may also rely on "cultural matching" processes, preferring candidates who enjoy similar activities and have selfpresentation styles aligning with a firm's culture (Rivera 2012). This "sociability" characteristic may induce observations about whether someone would be a good colleague, a potential friend, or a coworker who is a good team player. These subjective sociability judgments have the potential to influence hiring decisions.

\section{Conceptual Model}

Jones Young and Powell (2015) suggest a theoretical model for hiring ex-offenders. In their model, characteristics of the offense (seriousness, type of offense, and how recent) and exoffender characteristics (gender, race, and social class) influence hiring manager perceptions of warmth and competence, which ultimately lead to hiring manager decisions. They also account for additional contextual variables, such as hiring manager factors (demographic similarity to applicant, concerns about stigma, perceived likelihood of coworker acceptance, etc.), organizational culture, person-job fit, and availability and awareness of governmental incentives, in ultimately influencing hiring manager decisions. I draw upon Jones Young and Powell's (2015) model to create a hiring decision model, shown in Figure 1. 


\section{Figure 1.}

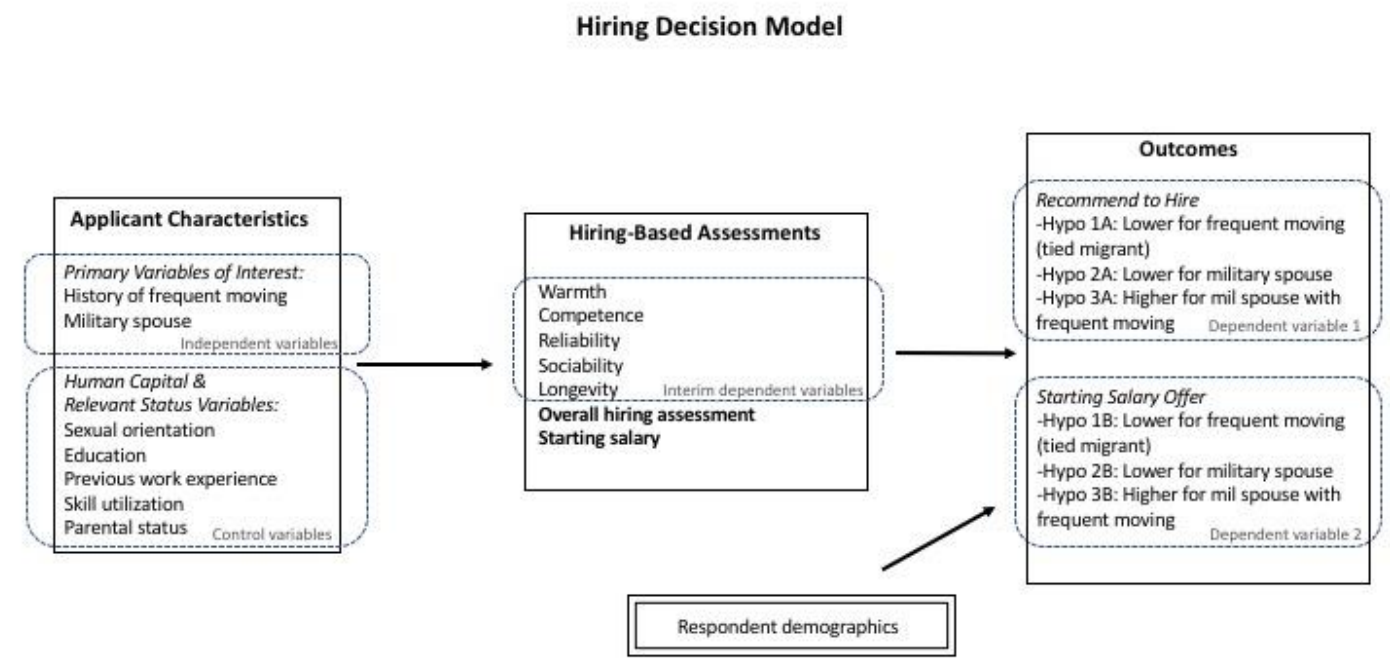

In this model, applicant characteristics lead to hiring-based assessments, which ultimately determine two key outcomes: the decision to hire someone and their starting salary offer. The applicant characteristics include the primary variables of interest in this study, history of frequent moving (signaling a tied migrant), and whether the applicant is a military spouse ${ }^{2}$. Other human capital and status characteristics include sexual orientation, education, previous work experience, previous skill utilization, and parental status. Hiring decision makers then make hiring-based assessments - perceptions of warmth, competence, reliability, sociability, and longevity - that influence their overall hiring assessment of an applicant and starting salary offer. The demographics of respondents, who represent hiring decision makers, also may influence hiring outcomes. The two primary outcomes are each motivated by three hypotheses, which are detailed above.

2 It is outside of the scope of this article to review the robust literature on processes that determine how, when, and why individuals decide to seek employment. This article focuses on the demand side of the equation; how employers evaluate individuals who are looking for work as prospective job candidates. 


\section{DATA AND METHODS}

\section{Factorial Vignette Design}

This study examines how the public perceives military spouses as job applicants and potential workers using a factorial vignette survey. Factorial vignette surveys combine the strengths of experiments, such as control and fully crossed designs, with the assets of surveys, such as evaluating perceptions and attitudes (Rossi and Nock 1982). In a factorial vignette survey, standardized fictitious descriptions are presented to respondents in which selected characteristics describing the object(s) are simultaneously manipulated, with the entire vignette population representing all possible combination of characteristics and dimensions (Wallander 2009). Respondents are then asked to review a sample "deck" of vignettes - a sample of the entire vignette population - that randomly vary characteristics so that many manipulations can be incorporated into a single experiment (Jasso 2006). Factorial vignette surveys are particularly helpful for examining the mechanisms behind human judgments or evaluations (Wallander 2009), and in this case, which characteristics are most salient when evaluating job candidates. In this study, several factors were varied generating 192 unique vignettes. To empirically test the aforementioned hypotheses, over 650 respondents $(\mathrm{N}=662)$ evaluated a randomized "deck" of 10 short vignettes describing a fictitious person seeking employment. The unit of analysis is the vignette, so 662 respondents evaluating 10 vignettes each resulted in 6,620 unique data points. After reading each vignette, which varies several employment-relevant characteristics of the applicant, respondents answer several questions evaluating the applicant. Respondents were shown an example vignette, along with the standard evaluative questions, before beginning the assessment (see Appendix A for details). 


\section{Sample}

This vignette survey was fielded to a sample of Amazon Mechanical Turk (Mturk) respondents. Mturk respondents provide a more representative sample than the typical pool of undergraduate students often used in psychology and sociology, although they tend to be younger than nationally representative survey samples (Weinberg, Freese, and McElhattan 2014). Mturk data have proven to be high quality based on manipulation checks, completion time, item nonresponse, and lack of variation in response (Weinberg et al. 2014). By using a more diverse and representative sample, the results better reflect attitudes among the general population who may encounter military spouses.

\section{Key Variables}

The primary experimental treatment is whether the woman described in a short vignette (see Appendix $A$ for a sample vignette) is married to someone who is on active duty in the military or not. While employment challenges occur for military spouses who are both men and women (see Hisnanick and Little 2015), 93\% of military spouses are women, therefore this study focuses on women who are married to someone serving in the military (Bradbard et al. 2016). An additional six characteristics are varied within each vignette to determine other mechanisms underlying observed employment gaps between military and civilian spouses. These additional characteristics, outlined in Figure 2, include sexual orientation (married to a woman or a man), education level (high school diploma or bachelor's degree), previous work experience (volunteering, part-time, or full-time), skill utilization (skills under-utilized or appropriately utilized at most recent position), history of frequent moving (has the same job for the past five years or three jobs in the last five years due to moving), and parental status (has one child or no children). The design does not state the military member's rank or branch and leaves race 
unstated. The instrument also solicits respondent demographic data, including the respondent's own military experience, whether any family members have served in the military, employment status, and whether the respondent has ever been responsible for hiring.

\section{Figure 1. Experimental Design}

\begin{tabular}{ll}
\hline Applicant Characteristics & Evaluation Ratings \\
\hline Spouse & Warmth \\
Military & Competence \\
Civilian & Reliability \\
Sexual Orientation & Sociability \\
Wife & Longevity \\
Husband & Overall hiring assessment \\
Geographic History & Starting salary \\
Mobile & \\
Stable & \\
Previous Work & \\
Experience & \\
Volunteer & \\
Part-time & \\
Full-time & \\
Skills & \\
Under-utilized & \\
Utilized & \\
Education & \\
High School & \\
Bachelor's & \\
Parent & \\
One child & \\
No children &
\end{tabular}

The dependent variables are composed of the evaluations respondents made about each vignette. For each vignette, respondents answer questions which assess the fictitious applicant's competence, reliability as a worker, estimated likelihood of the applicant remaining with the company for three or more years, likelihood of having a friendship with the applicant outside of work, desire to have the applicant as a co-worker, overall likelihood of recommending the 
applicant be hired, and the anticipated starting salary (see Appendix for exact question wording). All measures except for salary were evaluated on a scale from 1 to 7 , with 1 representing "not at all likely" and 7 representing "extremely likely." Using a number matching scale, in which respondents move a marker to a point on an ordered number scale, allows respondents to mark a point on a continuum instead of being constrained to a limited set of ordered categories (Jasso 2006; Wallander 2009). The salary question is presented as multiple choice and provides four options within the typical salary range for a Human Resources Assistant, the position in the vignette ( $\$ 25,000$ - $\$ 29,999$ at the low end to $\$ 40,000$ - $\$ 44,999$ at the high end). An open-ended question at the conclusion of the ten vignettes asked respondents to reflect holistically on what characteristics emerged as the most desirable from a hiring perspective, and what characteristics were "red flags" that made them hesitant to hire an applicant.

\section{Human Capital \& Relevant Status Variables}

The analytic models control for human capital and relevant status variables that previous research indicates are important, such as sexual orientation, education, previous work experience, skill utilization, and parental status. From a human capital perspective, education and work experience are important determinants of how job candidates are perceived and potential market wage (Cooke and Speirs 2005; Lakhani 1994; Schwartz et al. 1991). While more education generally leads to higher wages, military spouses with higher levels of education may experience a more negative impact from moving, citing career disruptions and the difficulty of re-establishing a professional network (Castaneda and Harrell 2007). Moving and interrupted work history can result in military spouses accepting volunteer or part-time work (nonstandard employment) when they would prefer full-time work, or accepting jobs that underutilize their skills and experience (mismatched or underemployment). Pedulla (2016) found that nonstandard 
and mismatched employment signals concerns with competence and commitment to prospective employers, and that women face a strong penalty for skills underutilization. Part-time and temporary work may also serve as a proxy for parental status, which could compound the established motherhood penalty (Correll, Benard, and Paik 2007; Pedulla 2016). Therefore, controlling for education level (High School diploma or Bachelor's degree), most recent work experience (full-time, part-time, or volunteer), and whether the applicant's skills in her most recent position were well utilized or not are important.

In addition to frequent moves resulting in career disruption, parenting demands are another key factor influencing the employment of military spouses (Hosek and Wadsworth 2013), and how employers may subsequently evaluate them as job candidates. There are logistical issues that arise when trying to balance employment and the demands of a military lifestyle, as the frequent, long-duration absences of service members results in the majority of daily parenting duties falling to the spouse, with many spouses reporting childcare as a pressing concern influencing their ability to obtain employment (Castaneda and Harrell 2007; Hosek and Wadsworth 2013). Traditional gender role socialization further exacerbates this dynamic as it often falls on the wife to coordinate moving logistics - a version of the "second shift" - coupled with the normative expectations that military spouses contribute volunteer labor to military units and installations (Castaneda and Harrell 2007; Cooke and Speirs 2005; Cooney et al. 2011; Harrell et al. 2004). Potential employers may assume that all military spouses are mothers due to stereotypes about military families, and while $74 \%$ of military spouses have children under the age of 18, not all military spouses are parents (Bradbard et al. 2016). Since employer pay evaluate mothers differently than non-mothers, parenthood status is also controlled for in the analysis (one child or no children). 
Finally, sexual orientation may influence employer hiring decisions. Several recent audit studies have found lesbian and gay individuals continue to be discriminated against in the labor market (Gaddis 2015; Mishel 2016; Tilcsik 2011). Conversely, intersecting identities can mitigate one another, for instance, the effeminate stereotypes of being gay counteract the threatening stereotypes associated with Black men, leading to gay Black men experiencing less discrimination than gay White men in the hiring process (Pedulla 2014). The status of being a military spouse may hold similar mediating effects on being married to someone of the same gender, so the analysis controls for how lesbian women are evaluated compared to straight/heterosexual women.

Analysis

Evidence of differential treatment between tied/stable migrants and between military and civilian spouses comes from comparing the differences in means across outcomes, as well as multivariate regression to see which variables are significant when accounting for respondent demographics and the characteristics of each potential job applicant posed in the vignette. To examine the first two parts of the conceptual model (see Figure 1) - applicant characteristics and hiring-based assessments - difference of means t-tests are used to determine whether the results significantly differ.

The final box of the conceptual model (see Figure 1) illustrates the two outcomes, hiring recommendation and starting salary offer, and I use regression models to test these two outcomes of interest. Factorial vignette studies produce data at two levels: the vignette level and the individual respondent level. Each respondent in this study evaluated 10 vignettes, so the vignette-level data are not independent observations, thus the Ordinary Least Squares (OLS) regression assumption of uncorrelated error terms is violated (Gordon 2010). OLS regression 
could result in an inflated standard error, leading to a Type 1 error: the risk of the null hypothesis being incorrectly rejected. Hierarchical linear models are often used in factorial vignette studies (Hox, Kreft, and Hermkens 1991; Jasso 2006) and are most appropriate for these data. Hierarchical linear models account for the fact that each respondent evaluated 10 vignettes by "nesting" two linear regression equations in order to evaluate the outcome of interest (Hox et al. 1991). In this case, the evaluations of 192 vignettes (level 1 units) are nested within 662 respondents (level 2 units). Results are based on hierarchical multi-level models for two primary outcomes: overall hiring assessment and starting salary offer.

The initial baseline model does not allow the slope to differ and assumes respondents follow the same rules in evaluating each vignette (Grilli and Rampichini 2005; Hox et al. 1991; Jasso 2006):

$$
\mathrm{y}_{i j}=\beta_{0}+\Sigma \beta_{i j} \mathrm{X}_{i j}+\varepsilon_{i j}
$$

where $\mathrm{y}_{i j}$ is the response for vignette $j$ made by respondent $i, \mathrm{X}_{i j}$ is the value of the vignette characteristics for vignette $j$ made by the respondent $i, \beta_{0}$ is the intercept, and $\varepsilon_{i}$ is the random error. The full model allows for variation of both the intercept and slope, and takes the form:

$$
\mathrm{y}_{i j}=\beta_{0 i j}+\Sigma \beta_{i j} \mathrm{X}_{i j}+\varepsilon_{i j}
$$

where $\mathrm{y}_{i j}$ is the response for vignette $j$ made by respondent $i, \mathrm{X}_{i j}$ are the applicant characteristics of the fictitious vignette $j$ made by respondent $i, \beta_{0 i j}$ are the regression coefficients within respondent $i$, and $\varepsilon_{i j}$ is the random error (Grilli and Rampichini 2005; Hox et al. 1991; Jasso 2006). Half of respondents (47\%) in this sample have had a job in which they were responsible for hiring, and all analyses are limited to only those respondents. This restricted sample best reflects the population of interest - hiring agents - and provides statistically conservative 
estimates for the variables of interest ${ }^{3}$; see Appendix $B$ for analyses replicated using the full sample.

\section{RESULTS}

I begin by presenting respondent demographics. Next, I examine the first outcome of interest, overall hiring assessment. I compare how military and civilian spouses are evaluated as job candidates and how frequent moving interacts with military spouse status (testing Hypotheses $1 A, 2 A$ and $3 A$ ). I illustrate how hiring-based assessments - perceptions of warmth, competence, reliability, likelihood of being at the job long term, and sociability - mediate how comparable military and civilian spouses are evaluated. Finally, I depict results for the second outcome of interest - starting salary information - and explore how frequent moving and military spouse status leads to varying salary offers, testing Hypotheses $1 B, 2 B$ and $3 B$.

\section{Respondent Characteristics}

Table 1 shows how reflective the Mturk sample is compared to the population of the United States, broken down by whether respondents have ever been responsible for hiring. Compared to the national population, this sample is more educated, younger, and more likely to be employed (United States Census Bureau 2010). Respondents include slightly more women (54\%) than men (46\%), and are mostly straight/heterosexual (90\%). This sample includes a higher proportion of individuals who identify as lesbian, gay, or bisexual (LGB) (10\%), compared to population-level estimates of 4\% of Americans identifying as LGB (Gates 2011; The Williams Institute 2016). Population-level data on sexual orientation are difficult to

\footnotetext{
${ }^{3}$ All analyses presented in this paper have been replicated on the full sample. The results are similar in terms of direction and magnitude of the coefficients, but some results that are not statistically significant in the restricted hiring experience sample are statistically significant in the full sample due to the larger sample size (N increases from 317 to 662). See Appendix $B$ for results from the full sample.
} 
measure, so the number of people who identify as "something else" within the population are not available to include in Table 1 (Gates 2011). A sizeable majority of the sample are White (80\%), with the remaining 20\% identifying as Black (9\%), Asian (5\%), Hispanic (4\%), and Multiracial (2\%). Hispanics are under-represented in this sample (4\% compared to $16 \%$ in the population). Most individuals have attended some college or have a post-secondary degree (72\%), and an additional $19 \%$ obtained a graduate degree, indicating the sample has higher rates of educational attainment compared to the national average of $48 \%$ and $11 \%$, respectively. More than half of the sample (65\%) are between the ages of 18 and 39, with the remaining in their 40s (19\%), 50s (11\%), or 60s (5\%). Just under half the sample are parents $(47 \%)$, which is lower than the national average of $66 \%$. A small number of respondents are actively serving in the military or are veterans $(6 \%)$, which is similar to the national rate of $8 \%$. More than half of respondents $(52 \%)$ have a family member who has served in the military, which is about 9 percentage points lower than the national average of $61 \%$ (Pew Research Center 2011). Most respondents are currently employed (81\%), and of those currently employed, most people have full-time jobs ( $81 \%$ of those employed, $66 \%$ of the total sample), which is similar to the broader population (Bureau of Labor Statistics 2016). Finally, about half of the sample (47\%) have ever had a position in which they were responsible for hiring. Table 1 shows those who have previous hiring experience are relatively similar to those without previous hiring experience. The differences between hiring experience emerge in two primary ways: those with previous hiring experience tend to be better educated and older than those without hiring experience. Those with previous hiring experience are also more likely to have a family member who has ever served in the military, be currently employed, and if employed, working full-time. Since half the sample (47\%) have hiring experience, it is beneficial to limit the analysis to those respondents to more 
accurately test what may be occurring in the "real world" outside of experimental control. This restricted sample best reflects the population of interest - hiring agents - and provides statistically conservative estimates for the variables of interest ${ }^{4}$; see Appendix $B$ for analyses replicated using the full sample. All results presented in this analysis are limited to respondents with previous hiring experience.

\footnotetext{
${ }^{4}$ All analyses presented in this paper have been replicated on the full sample. The results are similar in terms of direction and magnitude of the coefficients, but some results that are not statistically significant in the restricted hiring experience sample are statistically significant in the full sample due to the larger sample size (N increases from 317 to 662). See Appendix $B$ for results from the full sample.
} 
Table 1. Respondent Characteristics by Previous Hiring Experience

\begin{tabular}{|c|c|c|c|c|}
\hline & \multicolumn{3}{|c|}{ Sample } & \multirow[t]{4}{*}{ Population } \\
\hline & \multirow{2}{*}{\multicolumn{2}{|c|}{$\begin{array}{c}\text { Ever } \\
\text { Responsible } \\
\text { for Hiring }\end{array}$}} & \multirow[b]{3}{*}{ Total } & \\
\hline & & & & \\
\hline & Yes & No & & \\
\hline \multicolumn{5}{|l|}{ Gender } \\
\hline Man & 50 & 42 & 46 & 49 \\
\hline Woman & 50 & 58 & 54 & 51 \\
\hline Total & 100 & 100 & 100 & 100 \\
\hline \multicolumn{5}{|l|}{ Sexual Orientation } \\
\hline Straight / Heterosexual & 90 & 90 & 90 & 96 \\
\hline Gay / Lesbian & 6 & 3 & 4 & 2 \\
\hline Bisexual & 3 & 7 & 5 & 2 \\
\hline Something Else & 1 & 1 & 1 & N/A \\
\hline Total & 100 & 100 & 100 & 100 \\
\hline \multicolumn{5}{|l|}{ Race/Ethnicity } \\
\hline White & 83 & 76 & 80 & 75 \\
\hline Black & 5 & 12 & 9 & 14 \\
\hline Hispanic & 4 & 4 & 4 & 16 \\
\hline Asian & 5 & 5 & 5 & 5 \\
\hline Pacific islander & 0.6 & 0.3 & 0.5 & 0.2 \\
\hline Multiracial & 2 & 3 & 2 & 6 \\
\hline Total & 100 & 100 & 100 & 116 \\
\hline \multicolumn{5}{|l|}{ Education } \\
\hline High School Diploma & 5 & 12 & 9 & 28 \\
\hline Some College & 20 & 23 & 22 & 21 \\
\hline Associate's & 9 & 12 & 10 & 8 \\
\hline Bachelor's & 44 & 37 & 40 & 19 \\
\hline Graduate / Professional & 22 & 16 & 19 & 11 \\
\hline Total & 100 & 100 & 100 & 87 \\
\hline \multicolumn{5}{|l|}{ Age } \\
\hline $18-29$ & 15 & 40 & 28 & 15 \\
\hline $30-39$ & 36 & 38 & 37 & 13 \\
\hline $40-49$ & 26 & 12 & 19 & 14 \\
\hline $50-59$ & 14 & 8 & 11 & 13 \\
\hline $60-69$ & 7 & 3 & 5 & 9 \\
\hline $70-79$ & 1 & 0 & 1 & 5 \\
\hline Total & 100 & 100 & 100 & 69 \\
\hline \multicolumn{5}{|l|}{ Parent } \\
\hline Yes & 55 & 40 & 47 & 66 \\
\hline No & 45 & 60 & 53 & 34 \\
\hline Total & 100 & 100 & 100 & 100 \\
\hline \multicolumn{5}{|l|}{ Active Military/Veteran } \\
\hline Yes & 8 & 5 & 6 & 8 \\
\hline
\end{tabular}




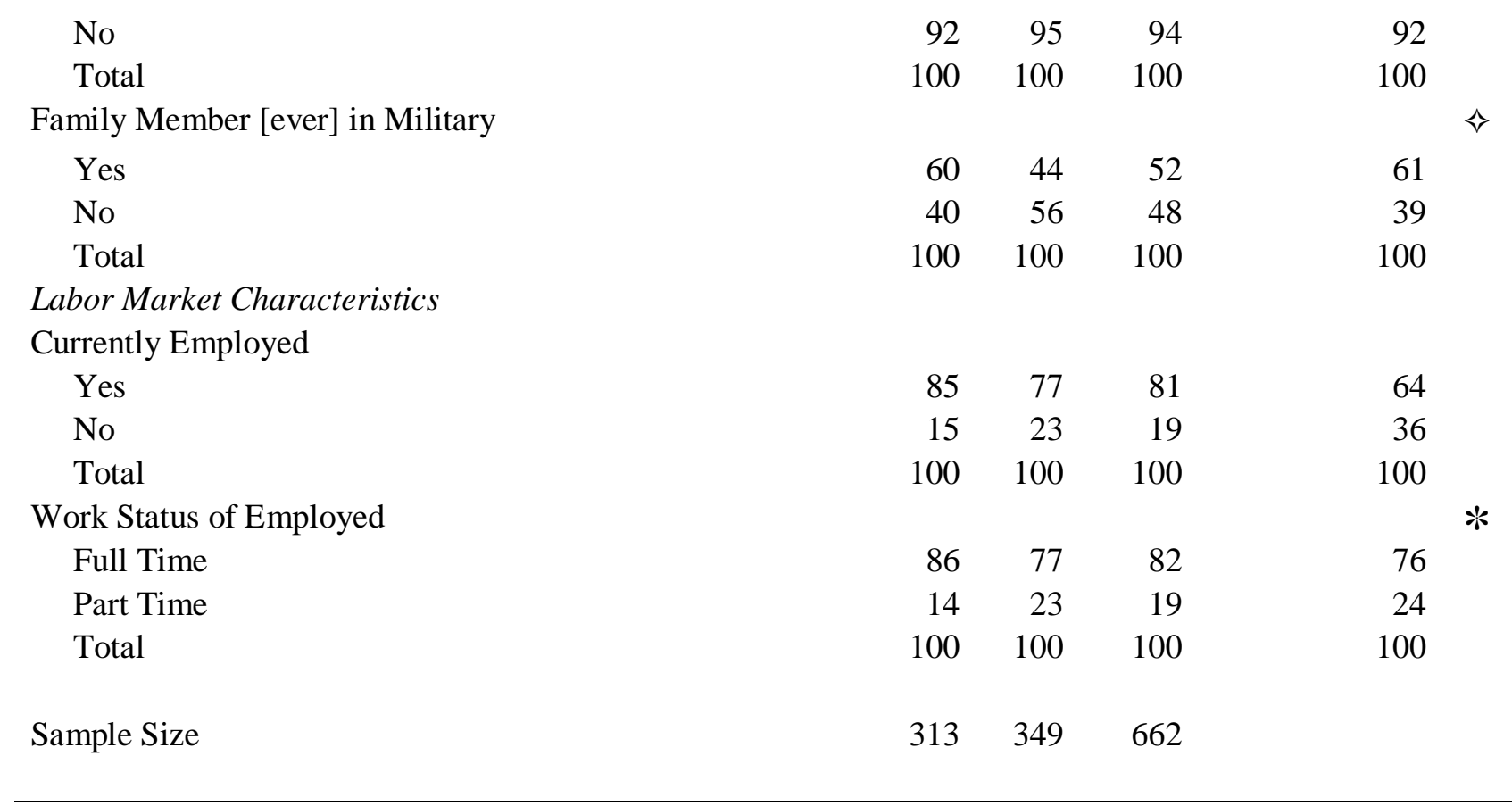

Population demographics are from the U.S. Census Bureau 2010 unless noted.

+ The Williams Institute 2016, Same-Sex Couples and LGBT Demographic Data

$\diamond$ Pew Research Center 2011, The Military-Civilian Gap: Fewer Family Connections

* Bureau of Labor Statistics 2016

Population-level data on sexual orientation are difficult to measure, so the number of people who identify as "something else" are not available (Gates 2011).

\section{Outcome 1: Hiring Recommendation}

This section focuses on the overall assessment rating, which asked "How likely would you be to hire this applicant?" An initial difference of means test, shown in Table 2, shows how applicant characteristics influence the hiring recommendation score. The results suggest applicant characteristics do not lead to statistically different outcomes between military and civilian spouses; there are no statistically significant differences between military and civilian spouses on this outcome. Both education and history of geographic mobility (moving frequently vs. geographic stability) have statistically significant main effects on hiring recommendation ( $\mathrm{p}<$ $.001)$. 
Table 2. Difference of Means for Hiring Outcome by Applicant Characteristics

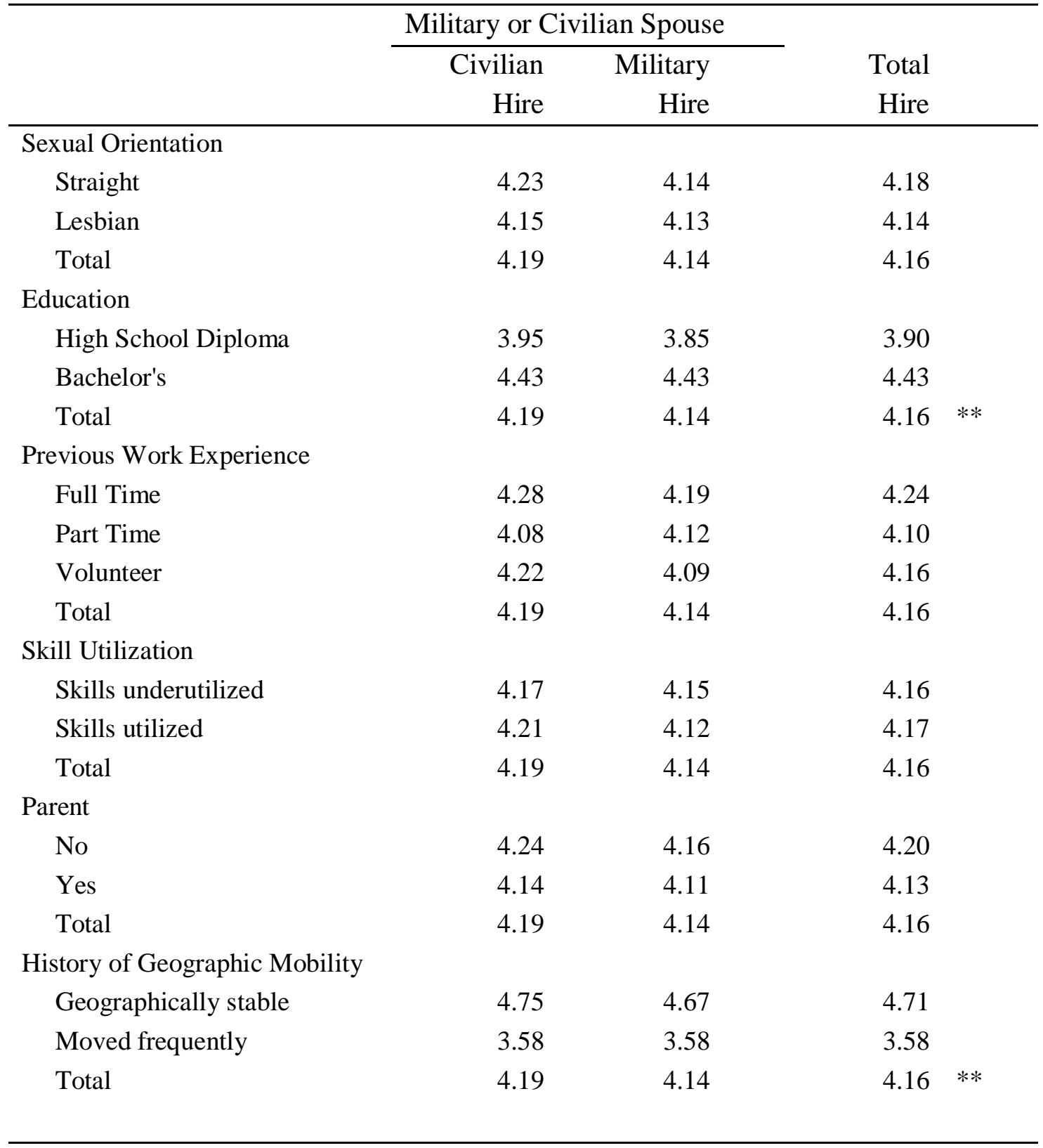

Note: Mean hiring scores are presented; applicants were rated on a scale of 1 (low) to 7 (high). There are no statistically significant differences between military and civilian spouses.

$* \mathrm{p}<.05 * * \mathrm{p}<.01$ (two-tailed tests) 
Continuing to examine hiring assessment, Table 3 presents results from a difference of means test showing the interaction of military spouse status and frequent moving. The first two columns show that for those with a history of geographic stability, there are not any statistically significant differences between civilian and military spouses. The latter two columns show the differences between military and civilian spouses for those who have a history of frequent moving, signaling their tied migrant status. There are no statistically significant differences between how military and civilian spouses are rated when both have a history of moving frequently. The final column shows the main effect of each variable on the hiring outcome; education is the only variable that is statistically significant $(\mathrm{p}<.001)$. Table 2 and Table 3 collectively indicate applicant characteristics do not lead to statistically different outcomes between military and civilian spouses, nor between those with a history of geographic stability or moving frequently. 
Table 3. Difference of Means for Hiring Outcome by Applicant Characteristics

\begin{tabular}{|c|c|c|c|c|c|c|}
\hline & \multicolumn{4}{|c|}{$\begin{array}{c}\text { Interaction of Military Spouse Status \& } \\
\text { Geographic Mobility }\end{array}$} & \multirow{3}{*}{$\begin{array}{l}\text { Total } \\
\text { Hire }\end{array}$} & \\
\hline & \multirow{2}{*}{$\begin{array}{r}\text { Civ-Stable } \\
\text { Hire }\end{array}$} & \multirow{2}{*}{$\begin{array}{r}\text { Mil-Stable } \\
\text { Hire }\end{array}$} & \multirow{2}{*}{$\begin{array}{c}\text { Civ-Mobile } \\
\text { Hire }\end{array}$} & \multirow{2}{*}{$\begin{array}{c}\text { Mil-Mobile } \\
\text { Hire }\end{array}$} & & \\
\hline & & & & & & \\
\hline \multicolumn{7}{|l|}{ Sexual Orientation } \\
\hline Straight & 4.75 & 4.61 & 3.68 & 3.65 & 4.18 & \\
\hline Lesbian & 4.75 & 4.74 & 3.48 & 3.50 & 4.14 & \\
\hline Total & 4.75 & 4.67 & 3.58 & 3.58 & 4.16 & \\
\hline \multicolumn{7}{|l|}{ Education } \\
\hline High School Diploma & 4.46 & 4.29 & 3.42 & 3.38 & 3.90 & \\
\hline Bachelor's & 5.03 & 5.06 & 3.75 & 3.78 & 4.43 & \\
\hline Total & 4.75 & 4.67 & 3.58 & 3.58 & 4.16 & $* *$ \\
\hline \multicolumn{7}{|l|}{ Previous Work Experience } \\
\hline Full Time & 4.87 & 4.76 & 3.65 & 3.62 & 4.24 & \\
\hline Part Time & 4.65 & 4.63 & 3.49 & 3.61 & 4.01 & \\
\hline Volunteer & 4.73 & 4.63 & 3.61 & 3.50 & 4.16 & \\
\hline Total & 4.75 & 4.67 & 3.58 & 3.58 & 4.16 & \\
\hline \multicolumn{7}{|l|}{ Skill Utilization } \\
\hline Skills underutilized & 4.72 & 4.74 & 3.59 & 3.58 & 4.16 & \\
\hline Skills utilized & 4.78 & 4.62 & 3.57 & 3.58 & 4.17 & \\
\hline Total & 4.75 & 4.67 & 3.58 & 3.58 & 4.16 & \\
\hline \multicolumn{7}{|l|}{ Parent } \\
\hline No & 4.81 & 4.75 & 3.63 & 3.57 & 4.20 & \\
\hline Yes & 4.69 & 4.60 & 3.53 & 3.59 & 4.13 & \\
\hline Total & 4.75 & 4.67 & 3.58 & 3.58 & 4.16 & \\
\hline
\end{tabular}

Note: Mean hiring scores are presented; applicants were rated on a scale of 1 (low) to 7 (high).

$* \mathrm{p}<.05 * * \mathrm{p}<.01$ (ANOVA test with bonferroni adjustment comparing civ/mil stable and civ/mil mobile) There are no statistically significant differences between military and civilian spouses. 
Table 4. Difference of Means Hiring-Based Assessments

\begin{tabular}{|c|c|c|c|c|c|c|c|c|}
\hline & \multicolumn{3}{|c|}{$\begin{array}{c}\text { History of } \\
\text { Geographic Mobility }\end{array}$} & \multirow[b]{2}{*}{ Total } & \multicolumn{3}{|c|}{ Military or Civ Spouse } & \multirow[b]{2}{*}{ Total } \\
\hline & $\begin{array}{r}\text { Geo } \\
\text { Stable }\end{array}$ & $\begin{array}{r}\text { Moved } \\
\text { Freq }\end{array}$ & & & Civilian & Military & & \\
\hline Warmth & 4.87 & 4.59 & ** & 4.73 & 4.68 & 4.79 & ** & 4.73 \\
\hline Competence & 5.21 & 4.81 & ** & 5.02 & 4.97 & 5.07 & $*$ & 5.02 \\
\hline Reliability & 4.86 & 4.42 & ** & 4.64 & 4.60 & 4.68 & & 4.64 \\
\hline Sociability & 4.26 & 3.95 & ** & 4.11 & 4.08 & 4.14 & & 4.11 \\
\hline Longevity & 5.01 & 2.65 & ** & 3.86 & 4.11 & 3.61 & $* *$ & 3.86 \\
\hline
\end{tabular}

Note: Mean assessment scores are presented; applicants were rated on a scale of 1 (low) to 7 (high).

$* \mathrm{p}<.05 * * \mathrm{p}<.01$ (two-tailed tests)

Because respondents were asked to evaluate different hiring-based assessments that likely influence an overall hiring decision, Table 4 presents those assessments broken down by the key factors of interest. These hiring-based assessments include perceived warmth, competence, reliability, sociability, and longevity (their likelihood of staying with the company for several years). Table 4 presents difference of means tests comparing those with a history of frequent moving, and secondly, comparing military or civilian spouses. For every assessment, individuals with a history of geographic stability were rated higher than those who had a history of moving frequently; these results are statistically significant $(\mathrm{p}<.01)$. Secondly, military spouses were rated at statistically significant higher levels than civilian spouses for warmth and competence, but were rated statistically lower for longevity. The average score is 4.11 for civilian spouses and 3.61 for military spouses $(\mathrm{p}<.01)$. This suggests military spouses receive a premium in terms of overall assessment, but are penalized when decision makers are considering their potential for longevity with a company. 
Table 5. Difference of Means Hiring-Based Assessments, Interaction of Military Spouse Status \& Geographic Mobility

\begin{tabular}{lrrrrr}
\hline & $\begin{array}{r}\text { Civ- } \\
\text { Stable }\end{array}$ & $\begin{array}{r}\text { Mil- } \\
\text { Stable }\end{array}$ & $\begin{array}{r}\text { Civ- } \\
\text { Mobile }\end{array}$ & $\begin{array}{c}\text { Mil- } \\
\text { Mobile }\end{array}$ & Total \\
\hline Warmth & 4.84 & 4.91 & 4.51 & $4.66 * *$ & 4.73 \\
Competence & 5.20 & 5.23 & 4.72 & $4.89 * *$ & 5.02 \\
Reliability & 4.85 & 4.86 & 4.33 & $4.50 * *$ & 4.64 \\
Sociability & 4.22 & 4.30 & 3.92 & 3.98 & 4.11 \\
Longevity & 5.36 & $4.63 * *$ & 2.74 & $2.56 * *$ & 3.86
\end{tabular}

Note: Mean assessment scores are presented; applicants were rated on a scale of 1 (low) to 7 (high).

$* \mathrm{p}<.05 * * \mathrm{p}<.01$ (two-tailed tests comparing civ/mil stable and civ/mil mobile separately).

Table 5 presents results from a difference of means test showing the interaction of military spouse status and frequent moving. The first two columns show applicants with a history of geographic stability, and military and civilian spouses are not rated differently on perceived warmth, competence, reliability, or sociability. Military spouses are rated lower on longevity (score of 4.63 compared to 5.36 for civilians, $\mathrm{p}<.01$ ). Thus, even if military spouse applicants show no sign of having moved in the past, they are rated lower than civilian spouses on their anticipated longevity with a company. The second set of columns show applicants who have a history of moving frequently. For those with a history of frequent moving, military spouses receive a statistically significant premium for perceived warmth, competence and reliability. However, the military spouse premium switches to a penalty when longevity is considered (score of 2.74 for civilians, 2.56 for military spouses, $\mathrm{p}<.01$ ). In sum, regardless of whether military spouses have actually moved frequently in the past or not, they are rated lower than comparable civilian spouses on anticipated longevity with a company. 
Table 6. Hiring Recommendation, Mixed-Effects Multilevel Regression Models

\begin{tabular}{|c|c|c|c|c|c|c|c|c|c|c|}
\hline & \multicolumn{2}{|l|}{ Baseline } & \multicolumn{2}{|l|}{ M 1} & \multicolumn{2}{|l|}{ M 2} & \multicolumn{2}{|l|}{ M 3} & \multicolumn{2}{|c|}{ M 4} \\
\hline \multicolumn{11}{|l|}{ Vignette Characteristics } \\
\hline \multirow[t]{2}{*}{ Military Spouse (Civilian) } & -0.07 & & -0.11 & $*$ & -0.11 & $*$ & 0.10 & $*$ & 0.10 & $*$ \\
\hline & $(0.04)$ & & $(0.06)$ & & $(0.05)$ & & $(0.04)$ & & $(0.04)$ & \\
\hline \multirow[t]{2}{*}{ Geographically Mobile (Stable) } & -1.16 & $* * *$ & -1.20 & $* * *$ & -1.20 & $* * *$ & -0.08 & & -0.09 & \\
\hline & $(0.04)$ & & $(0.06)$ & & $(0.05)$ & & $(0.05)$ & & $(0.05)$ & \\
\hline \multicolumn{11}{|c|}{ Military Spouse x Geo Mobile (Civ x Stable) } \\
\hline \multirow[t]{2}{*}{ Civilian Spouse x Moved Freq } & & & -1.20 & $* * *$ & -1.20 & $* * *$ & -0.08 & & -0.09 & \\
\hline & & & $(0.06)$ & & $(0.05)$ & & $(0.05)$ & & $(0.05)$ & \\
\hline \multirow[t]{2}{*}{ Military Spouse x Geo Stable } & & & -0.11 & $*$ & -0.11 & $*$ & 0.10 & $*$ & 0.10 & $*$ \\
\hline & & & $(0.06)$ & & $(0.05)$ & & $(0.04)$ & & $(0.04)$ & \\
\hline \multirow[t]{2}{*}{ Military Spouse x Moved Freq } & & & -1.23 & $* * *$ & -1.23 & $* * *$ & -0.14 & $*$ & -0.14 & $*$ \\
\hline & & & $(0.06)$ & & $(0.05)$ & & $(0.05)$ & & $(0.05)$ & \\
\hline \multirow[t]{2}{*}{ Bachelor's (High School) } & & & & & 0.56 & $* * *$ & 0.28 & $* * *$ & 0.28 & $* * *$ \\
\hline & & & & & $(0.04)$ & & $(0.03)$ & & $(0.03)$ & \\
\hline \multicolumn{11}{|l|}{ Previous Position (Full Time) } \\
\hline \multirow[t]{2}{*}{ Part-time } & & & & & -0.18 & $* * *$ & -0.10 & $* *$ & -0.10 & $* *$ \\
\hline & & & & & $(0.05)$ & & $(0.04)$ & & $(0.04)$ & \\
\hline \multirow[t]{2}{*}{ Volunteer } & & & & & -0.15 & $* *$ & -0.12 & $* *$ & -0.12 & $* * *$ \\
\hline & & & & & $(0.05)$ & & $(0.04)$ & & $(0.04)$ & \\
\hline \multirow[t]{2}{*}{ Skills utilized (Not Utilized) } & & & & & -0.02 & & -0.03 & & -0.03 & \\
\hline & & & & & $(0.04)$ & & $(0.03)$ & & $(0.03)$ & \\
\hline \multirow[t]{2}{*}{ Parent (No Children) } & & & & & -0.12 & $* *$ & -0.04 & & -0.04 & \\
\hline & & & & & $(0.04)$ & & $(0.03)$ & & $(0.03)$ & \\
\hline \multicolumn{11}{|l|}{ Hiring Based Assessments } \\
\hline \multirow[t]{2}{*}{ Warmth } & & & & & & & 0.17 & $* * *$ & 0.17 & $* * *$ \\
\hline & & & & & & & $(0.02)$ & & $(0.02)$ & \\
\hline \multirow[t]{2}{*}{ Competence } & & & & & & & 0.32 & $* * *$ & 0.32 & $* * *$ \\
\hline & & & & & & & $(0.02)$ & & $(0.02)$ & \\
\hline \multirow[t]{2}{*}{ Reliability } & & & & & & & 0.07 & $* * *$ & 0.07 & $* * *$ \\
\hline & & & & & & & $(0.01)$ & & $(0.01)$ & \\
\hline \multirow[t]{2}{*}{ Sociability } & & & & & & & 0.19 & $* * *$ & 0.18 & $* * *$ \\
\hline & & & & & & & $(0.02)$ & & $(0.02)$ & \\
\hline \multirow[t]{2}{*}{ Longevity } & & & & & & & 0.31 & $* * *$ & 0.31 & $* * *$ \\
\hline & & & & & & & $(0.01)$ & & $(0.01)$ & \\
\hline Constant & 4.76 & $* * *$ & 4.78 & $* * *$ & 4.69 & $* * *$ & -0.52 & $* * *$ & 0.26 & \\
\hline & $(0.06)$ & & $(0.06)$ & & $(0.07)$ & & $(0.14)$ & & $(0.28)$ & \\
\hline Respondent Variance & -0.20 & $* * *$ & -0.20 & $* * *$ & -0.18 & $* * *$ & -0.48 & $* * *$ & -0.55 & $* * *$ \\
\hline & $(0.05)$ & & $(0.05)$ & & $(0.05)$ & & $(0.05)$ & & $(0.05)$ & \\
\hline
\end{tabular}




\begin{tabular}{|c|c|c|c|c|c|c|c|c|c|}
\hline Vignette Variance & $\begin{array}{r}0.06 \\
(0.01)\end{array}$ & $* * *$ & $\begin{array}{r}0.06 \\
(0.01)\end{array}$ & $* * *$ & $\begin{array}{r}0.02 \\
(0.01)\end{array}$ & & $\begin{array}{l}-0.22 \\
(0.01)\end{array}$ & $* * *$ & $\begin{array}{l}-0.22 \\
(0.01)\end{array}$ \\
\hline -2 log-likelihood & $-4,931$ & & $-4,931$ & & $-4,815$ & & $-4,048$ & & $-4,029$ \\
\hline Chi-square & 858 & $* * *$ & 860 & $* * *$ & 1,175 & $* * *$ & 3,883 & $* * *$ & 3,954 \\
\hline $\mathrm{N}$ & 3,130 & & 3,130 & & 3,130 & & 3,130 & & 3,130 \\
\hline
\end{tabular}

Note: Reference groups and standard errors are in parentheses. Respondent demographics are added in Model 4, but are not shown here.

$* \mathrm{p}<.05 * * \mathrm{p}<.01 * * * \mathrm{p}<.001$ (two-tailed tests).

Table 6 depicts hierarchical multilevel regression models for the hiring outcome. The first column illustrates a baseline model with no controls, and in this model, military spouses and those with a history of frequent moving, on average, are rated lower than civilian spouses and those with geographic stability, respectively. Applicants who have a history of frequent moving are particularly penalized: they are rated 1.2 points lower, on a 7-point scale, than applicants who have a geographically stable history $(\mathrm{p}<.001)$. Model 1 is an interaction between military spouse and frequent moving. The results show that those who have a history of frequent moving are penalized: both military spouse and civilian applicants are rated about 1.2 points lower $(\mathrm{p}<$ .001). Military spouses who have a history of geographic stability receive a small penalty, about a tenth of a point $(\mathrm{p}<.05)$. Model 2 controls for the other applicant characteristics, and suggests those with a Bachelor's degree receive a half point premium $(\mathrm{p}<.001)$, and the penalty for moving frequently stays the same as Model 1. Model 3 accounts for the other hiring based assessments (e.g. perceptions of warmth and competence), which are all positively correlated with overall hiring recommendation $(\mathrm{p}<.001)$. This indicates that applicants who are positively evaluated on any one of these characteristics are more likely to be considered hirable overall. Controlling for these hiring based assessments substantially reduces the penalty for frequent moving, reducing it to less than a tenth of a point for civilian spouses (no longer statistically 
significant) and less than a quarter of a point (.15) for military spouses $(\mathrm{p}<.05)$. Finally, Model 4 adds respondent demographics 5 . Except for age, respondent demographics generally do not influence the evaluation of job candidates. Because the hierarchical linear model accounts for a random respondent level effect, and because of the random assignment of vignettes to respondents, including respondent demographics in regression models should have little effect on the estimates for predictors of interest.

Model 4 results mirror the difference of means test reported in Tables 3, 4, and 5. Net of controls for applicant characteristics, hiring-based assessments, and respondent demographics, military spouses receive a premium (about a tenth of a point higher, $\mathrm{p}<.05$ ) in overall hiring assessment compared to civilian spouses. This result rejects Hypothesis $2 A$. In the full model, after controlling for applicant characteristics, hiring-based assessments, and respondent demographics, the penalty for frequent moving decreases to only -.09 and is not statistically distinguishable from 0 , which rejects Hypothesis $1 A$. The interaction between military spouse and frequent moving shows military spouses with a history of geographic stability receive a premium - they are rated one tenth of a point higher than comparable applicants $(\mathrm{p}<.05)$, while military spouses who have moved frequently are penalized - they are rated lower $(.15$ points, $\mathrm{p}<$ .05) compared to civilian spouses who have also moved frequently.

\footnotetext{
${ }^{5}$ Due to the randomized experimental control of vignette studies, the results should be similar regardless of whether respondent demographics are included or omitted in models. Therefore, Model 4 produces nearly identical coefficients to the variables included in Model 3, while adding estimates of how respondent characteristics influence hireability judgments.
} 


\section{Figure 3.}

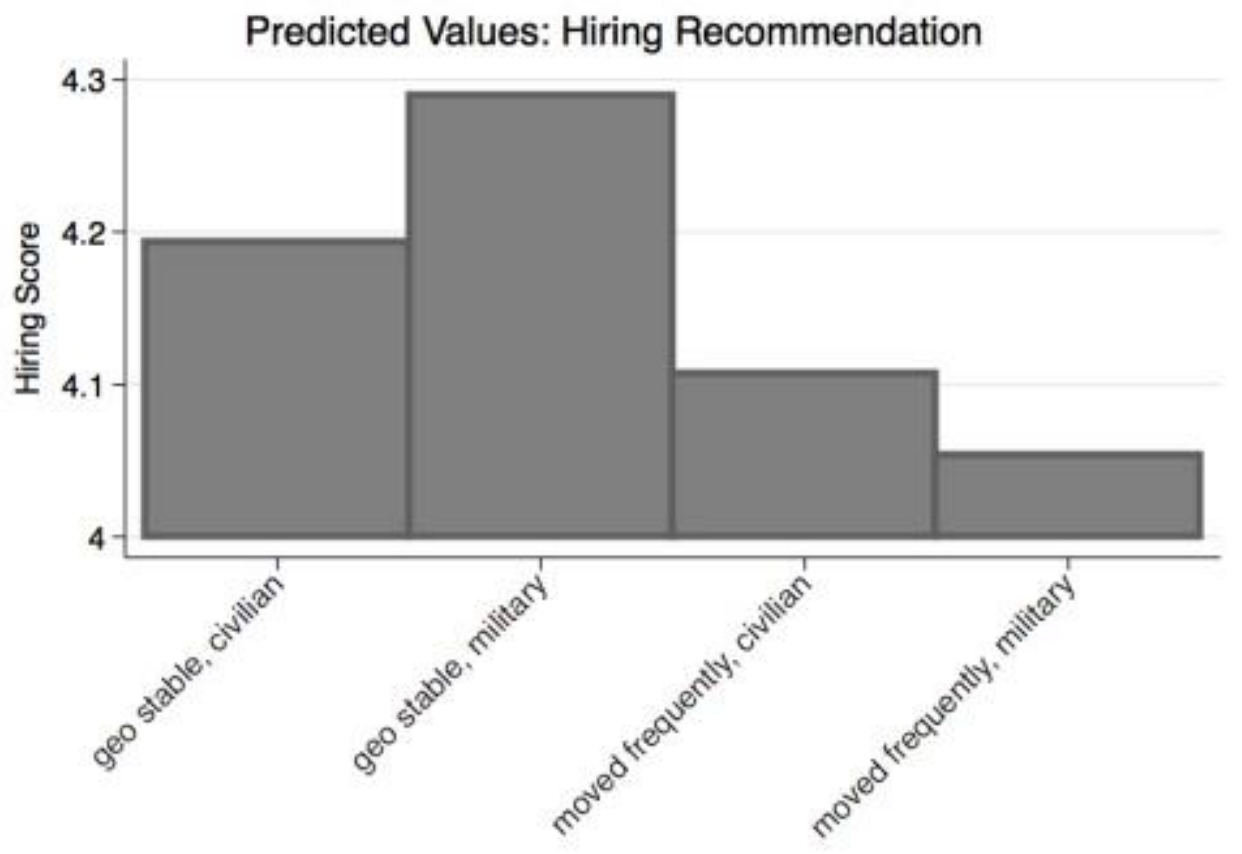

Figure 3 highlights the predicted hiring outcome of military and civilian spouses, comparing whether the applicant has a history of frequent moving or stability. The results show a nuanced picture: among women who have been geographically stable, military spouses are rated higher than civilian spouses (4.29 compared to 4.19). However, for applicants with a history of moving frequently, recursive tied migrants, the inverse is true: civilian spouses are rated higher than military spouses (4.11 compared to 4.05). These results suggest applicants with a stable geographic history are generally evaluated higher than those who have moved frequently, suggesting there is a penalty for tied migration. Military spouses with a stable geographic history are evaluated higher than civilians, but that premium switches to a penalty for military spouses with a history of moving frequently, in which case they are evaluated more harshly than civilians who have moved frequently. 


\section{Outcome Two: Stating Salary Offer}

Examining the initial salary offer respondents make to potential applicants is another indicator to understand how comparable civilian and military spouses may be evaluated. This question asked respondents, "The typical starting salary for this position is between $\$ 25,000$ $\$ 45,000$. In the event that you end up hiring this applicant, what would you offer her as a starting salary?" Respondents selected one of four possible choices in $\$ 5,000$ increments $(\$ 25,000$ $\$ 29,999$ at the low end to $\$ 40,000$ - $\$ 44,999$ at the high end). To aid in understanding salary differences, the mean income in each category is used for analysis. While starting salary offer is a process that occurs after an applicant is selected for the job, it is a useful proxy to understand how hiring decision makers are rating and evaluating a given candidate.

Table 7 presents results of a difference of means test between military and civilian spouses. Starting salary offers are relatively similar between civilian and military spouses; there are no statistically significant differences within any of the applicant characteristic categories. Education and previous work experience have a statistically significant main effect on starting salary offer. Similarly, Table 8 shows difference of means tests between military and civilian spouse applicants who have a history of geographic stability and separately, between military and civilian applicants who have a history of moving frequently. In each category, there are no statistically significant salary differences between military and civilian spouses. Both education and previous work experience have a statistically significant main effect on starting salary offer. These results suggest military/civilian spouse status and history of frequent moving are not salient characteristics for hiring agents when they determine starting salary offers. 
Table 7. Difference of Means for Salary Outcome by Applicant Characteristics

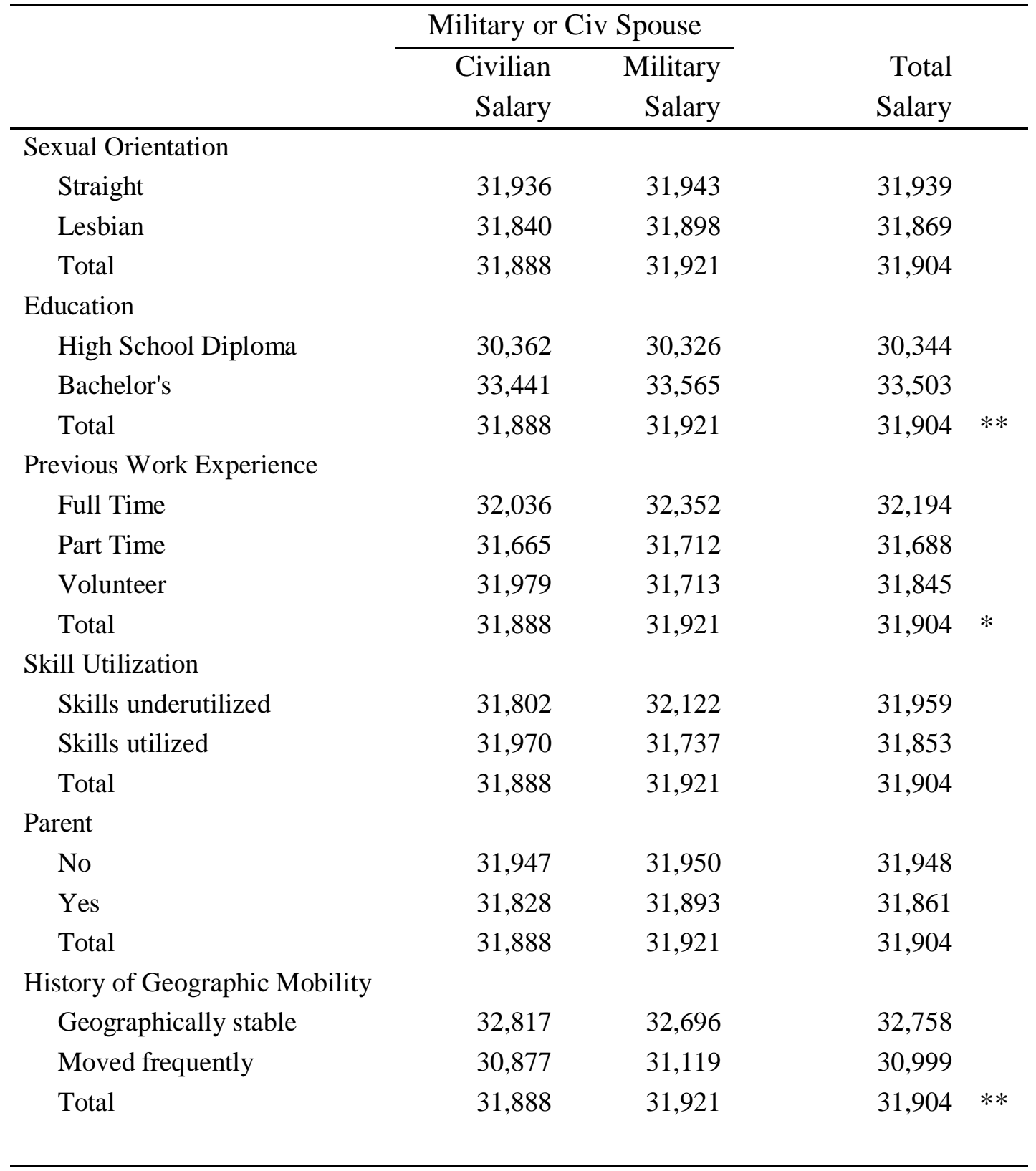

Note: Mean starting salary offers are presented. $* \mathrm{p}<.05 * * \mathrm{p}<.01$ (two-tailed tests).

There are no statistically significant differences between military and civilian spouses. 
Table 8. Difference of Means for Salary Outcome by Applicant Characteristics

\begin{tabular}{|c|c|c|c|c|c|c|}
\hline & \multicolumn{4}{|c|}{$\begin{array}{c}\text { Interaction of Military Spouse Status \& } \\
\text { Geographic Mobility }\end{array}$} & \multirow[b]{2}{*}{ Total } & \\
\hline & $\begin{array}{l}\text { Civ- } \\
\text { Stable } \\
\text { Salary }\end{array}$ & $\begin{array}{r}\text { Mil- } \\
\text { Stable } \\
\text { Salary }\end{array}$ & $\begin{array}{r}\text { Civ- } \\
\text { Mobile } \\
\text { Salary }\end{array}$ & $\begin{array}{r}\text { Mil- } \\
\text { Mobile } \\
\text { Salary }\end{array}$ & & \\
\hline \multicolumn{7}{|l|}{ Sexual Orientation } \\
\hline Straight & 32,884 & 32,740 & 30,918 & 31,123 & 31,939 & \\
\hline Lesbian & 32,752 & 32,652 & 30,838 & 31,115 & 31,869 & \\
\hline Total & 32,817 & 32,696 & 30,877 & 31,119 & 31,904 & \\
\hline \multicolumn{7}{|l|}{ Education } \\
\hline HS Diploma & 31,112 & 30,941 & 29,575 & 29,691 & 30,344 & \\
\hline Bachelor's & 34,493 & 34,505 & 32,255 & 32,593 & 33,503 & \\
\hline Total & 32,817 & 32,696 & 30,877 & 31,119 & 31,904 & $* *$ \\
\hline \multicolumn{7}{|c|}{ Previous Work Experience } \\
\hline Full Time & 33,096 & 33,366 & 30,921 & 31,334 & 32,194 & \\
\hline Part Time & 32,571 & 32,268 & 30,729 & 31,159 & 31,688 & \\
\hline Volunteer & 32,802 & 32,482 & 31,002 & 30,860 & 31,845 & \\
\hline Total & 32,817 & 32,696 & 30,877 & 31,119 & 31,904 & $*$ \\
\hline \multicolumn{7}{|l|}{ Skill Utilization } \\
\hline Skills underut. & 32,601 & 33,037 & 30,957 & 31,243 & 31,959 & \\
\hline Skills utilized & 33,020 & 32,406 & 30,798 & 30,997 & 31,853 & \\
\hline Total & 32,817 & 32,696 & 30,877 & 31,119 & 31,904 & \\
\hline \multicolumn{7}{|l|}{ Parent } \\
\hline No & 32,927 & 32,774 & 30,903 & 31,118 & 31,948 & \\
\hline Yes & 32,707 & 32,623 & 30,851 & 31,120 & 31,861 & \\
\hline Total & 32,817 & 32,696 & 30,877 & 31,119 & 31,904 & \\
\hline
\end{tabular}

Note: Mean starting salary offers are presented.

$* \mathrm{p}<.05 * * \mathrm{p}<.01$ (ANOVA test with bonferroni adjustment comparing civ/mil stable and civ/mil mobile).

There are no statistically significant differences between military and civilian spouses. 
Table 9. Starting Salary, Mixed-Effects Multilevel Regression Models

\begin{tabular}{|c|c|c|c|c|c|c|c|c|c|c|}
\hline & \multicolumn{2}{|l|}{ Baseline } & \multicolumn{2}{|l|}{ M 1} & \multicolumn{2}{|l|}{ M 2} & \multicolumn{2}{|l|}{ M 3} & \multicolumn{2}{|l|}{ M 4} \\
\hline \multicolumn{11}{|l|}{ Vignette Characteristics } \\
\hline \multirow{2}{*}{ Military Spouse (Civilian) } & 63.17 & & -45.43 & & -33.48 & & 265.95 & & 257.17 & \\
\hline & $(124.87)$ & & $(173.86)$ & & $(149.69)$ & & $(136.77)$ & & $(136.66)$ & \\
\hline \multirow[t]{2}{*}{ Geographically Mobile (Stable) } & $-1,868.76$ & $* * *$ & - & $* * *$ & $-1,941.34$ & $* * *$ & 30.68 & & 14.91 & \\
\hline & $(125.49)$ & & $\begin{array}{l}1,982.19 \\
(178.09)\end{array}$ & & $(153.42)$ & & $(173.49)$ & & $(173.21)$ & \\
\hline \multicolumn{11}{|c|}{ Military Spouse x Geo Mobile (Civ x Stable) } \\
\hline \multicolumn{3}{|l|}{ Civilian Spouse x Moved } & - & $* * *$ & $-1,941.34$ & $* * *$ & 30.68 & & 14.91 & \\
\hline \multicolumn{3}{|l|}{ Freq } & $\begin{array}{l}1,982.19 \\
(178.09)\end{array}$ & & $(153.42)$ & & $(173.49)$ & & $(173.21)$ & \\
\hline \multirow{2}{*}{$\begin{array}{l}\text { Military Spouse x Geo } \\
\text { Stable }\end{array}$} & & & -45.43 & & -33.48 & & 265.95 & & 257.17 & \\
\hline & & & $(173.86)$ & & $(149.69)$ & & $(136.77)$ & & $(136.66)$ & \\
\hline \multirow[t]{2}{*}{ Mil Spouse x Moved Freq } & & & $-1,802$ & $* * *$ & $-1,818.29$ & $* * *$ & 71.57 & & 58.18 & \\
\hline & & & $(175.1)$ & & $(150.71)$ & & $(176.22)$ & & $(175.95)$ & \\
\hline \multirow[t]{2}{*}{ Bachelor's (High School) } & & & & & $3,347.74$ & $* * *$ & $2,721.27$ & $* * *$ & $2,720.09$ & $* * *$ \\
\hline & & & & & $(107.94)$ & & $(99.01)$ & & $(98.9)$ & \\
\hline \multicolumn{11}{|l|}{ Previous Position (Full Time) } \\
\hline \multirow[t]{2}{*}{ Part-time } & & & & & -748.51 & $* * *$ & -554.94 & $* * *$ & -551.74 & $* * *$ \\
\hline & & & & & $(132.02)$ & & $(117.28)$ & & $(117.19)$ & \\
\hline \multirow[t]{2}{*}{ Volunteer } & & & & & -443.99 & $* * *$ & -390.00 & $* * *$ & -398.02 & $* * *$ \\
\hline & & & & & $(132.98)$ & & $(117.83)$ & & $(117.74)$ & \\
\hline \multirow[t]{2}{*}{ Skills utilized (Not Utilized) } & & & & & -225.31 & $*$ & -244.67 & $*$ & -250.16 & $* *$ \\
\hline & & & & & $(107.7)$ & & $(95.42)$ & & $(95.35)$ & \\
\hline \multirow[t]{2}{*}{ Parent (No Children) } & & & & & -160.74 & & 49.17 & & 47.32 & \\
\hline & & & & & $(107.8)$ & & $(103.12)$ & & $(102.99)$ & \\
\hline \multicolumn{11}{|l|}{ Hiring-Based Assessments } \\
\hline \multirow[t]{2}{*}{ Warmth } & & & & & & & 378.50 & $* * *$ & 385.27 & $* * *$ \\
\hline & & & & & & & $(78.42)$ & & $(78.1)$ & \\
\hline \multirow[t]{2}{*}{ Competence } & & & & & & & 789.90 & $* * *$ & 799.16 & $* * *$ \\
\hline & & & & & & & $(65)$ & & $(64.85)$ & \\
\hline \multirow[t]{2}{*}{ Reliability } & & & & & & & 184.64 & $* * *$ & 185.09 & $* * *$ \\
\hline & & & & & & & $(45.18)$ & & $(45.01)$ & \\
\hline \multirow[t]{2}{*}{ Sociability } & & & & & & & 486.84 & $* * *$ & 489.52 & $* * *$ \\
\hline & & & & & & & $(61.15)$ & & $(60.75)$ & \\
\hline \multirow[t]{3}{*}{ Longevity } & & & & & & & 475.46 & $* * *$ & 468.61 & $* * *$ \\
\hline & & & & & & & $(42.09)$ & & $(42)$ & \\
\hline & & & & & & & & & $(302.45)$ & \\
\hline Constant & 32,780 & $* * *$ & 32,834 & $* * *$ & 31,773 & $* * *$ & 20,440 & $* * *$ & 22,120 & $* * *$ \\
\hline & (185) & & (195) & & $(224)$ & & $(471)$ & & $(1,091)$ & \\
\hline
\end{tabular}




\begin{tabular}{|c|c|c|c|c|c|c|c|c|c|}
\hline Respondent Variance & $\begin{array}{r}7.90 \\
(0.05)\end{array}$ & $* * *$ & $\begin{array}{r}7.90 \\
(0.05)\end{array}$ & $* * *$ & $\begin{array}{r}7.93 \\
(0.04)\end{array}$ & $* * *$ & $\begin{array}{r}7.88 \\
(0.04)\end{array}$ & $* * *$ & $\begin{array}{r}7.77 \\
(0.04)\end{array}$ \\
\hline Vignette Variance & $\begin{array}{r}8.12 \\
(0.01)\end{array}$ & $* * *$ & $\begin{array}{r}8.12 \\
(0.01)\end{array}$ & $* * *$ & $\begin{array}{r}7.97 \\
(0.01)\end{array}$ & $* * *$ & $\begin{array}{r}7.84 \\
(0.01)\end{array}$ & $* * *$ & $\begin{array}{r}7.84 \\
(0.01)\end{array}$ \\
\hline-2 log-likelihood & $-30,000$ & & $-30,000$ & & $-30,000$ & & $-29,000$ & & $-29,000$ \\
\hline Chi-square & 221 & $* * *$ & 222 & $* * *$ & 126 & $* * *$ & 2,472 & $* * *$ & 2,551 \\
\hline $\mathrm{N}$ & 3,130 & & 3,130 & & 3,130 & & 3,130 & & 3,130 \\
\hline
\end{tabular}

Note: Reference groups and standard errors are in parentheses. Respondent demographics are added in Model 4, but are not shown here.

$* \mathrm{p}<.05 * * \mathrm{p}<.01 * * * \mathrm{p}<.001$ (two-tailed tests).

Table 9 includes multilevel regression models for starting salary offer. The first column shows a baseline model with no controls, and in this model, applicants who have moved frequently receive about a $\$ 1,800$ lower starting salary offer than those who have been geographically stable $(\mathrm{p}<.001)$. Model 1 adds an interaction between military spouse status and frequent moving. These results show that the salary distinctions between military and civilian spouses are minimal and not statistically significant; the primary difference remains among those who have moved frequently. In fact, among those who have moved frequently, civilian spouses experience more of a salary penalty $(-\$ 1,982)$ compared to military spouses $(-\$ 1,801)(\mathrm{p}<.001)$. Model 2 controls for applicant characteristics, and the salary penalties remain similar to Model 1; those who have moved frequently experience the most salary penalty $(\mathrm{p}<.001)$, and civilian spouses who have moved frequently fare worse than military spouses $(\mathrm{p}<.001)$. Applicants with a Bachelor's degree receive a higher salary offer $(\$ 3,347, \mathrm{p}<.001)$ than those with a High School diploma, and those who have most recently held part-time (-\$748) or volunteer positions $(-\$ 444)$ are penalized compared to those who were most recently working full-time $(\mathrm{p}<.001)$. Model 3 adds the other hiring-based assessments. The hiring assessments are all positively correlated and statistically significant $(\mathrm{p}<.001)$, suggesting that positive perceptions of warmth, 
competence, reliability, sociability, and longevity lead to a higher initial salary offer. When these hiring assessments are included in the model, the penalty for frequent moving diminishes and is no longer statistically significant. The premium for a Bachelor's degree reduces but remains significant $(\$ 2,721, \mathrm{p}<.001)$. The penalties for most recently working at a part-time job $(-\$ 554)$ or in a volunteer position $(-\$ 117)$ also reduce but remain significant $(\mathrm{p}<.001)$. The results for Model 4, which add respondent demographics, are nearly identical to Model 3. This is expected as hierarchical linear model accounts for a random respondent level effect, and because of the random assignment of vignettes to respondents, including respondent demographics in regression models should have little effect on the estimates for predictors of interest.

Figure 4

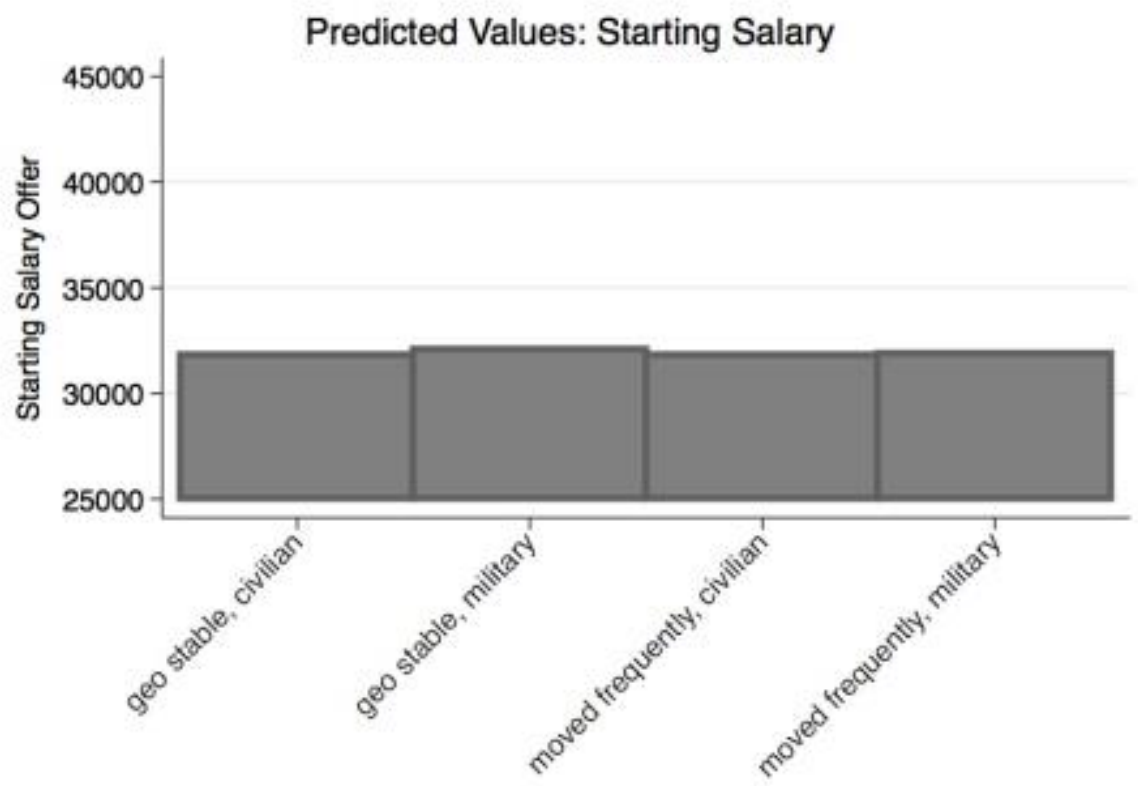

Figure 4 shows the predicted values of starting salary offer, illustrating the differences between geographic history and military and civilian spouses. Overall, military and civilian spouses do not receive disparate salary offers. After controlling for applicant characteristics, hiring-based assessments, and respondent demographics, there are no statistically significant 
differences in the starting salary offer between applicants who moved frequently and applicants who have been geographically stable. It is possible that frequent moving, signaling a pattern of tied migration, is not the most salient feature to hiring decision makers when determining a starting salary.

\section{FINDINGS}

First, the results show that hiring-based assessments are key indicators of hiring decision makers' overall hiring recommendation and starting salary offer. There is a tied migrant penalty: for every hiring-based assessment, those who had a history of moving frequently were rated lower than those with geographic stability. Military spouses receive a premium for most assessments, being evaluated as more warm, competent, reliable, and social. However, regardless of whether military spouses have actually moved frequently in the past or not, they are rated lower than comparable civilian spouses on anticipated longevity with a company.

Next, the initial primary outcome of interest is overall hiring recommendation. Results show that net of controls for applicant characteristics, hiring-based assessments, and respondent demographics, military spouses receive a premium (about a tenth of a point higher, $\mathrm{p}<.05$ ) in overall hiring assessment compared to civilian spouses. There were three hypotheses associated with this outcome. Hypothesis $1 A$ is applicants with a history of frequent moving (tied migrants) will receive lower hiring recommendations than comparable candidates with a history of geographic stability. This hypothesis is rejected. After controlling for applicant characteristics, hiring-based assessments, and respondent demographics, those with a history of frequent moving do not receive a lower hiring recommendation. Hypothesis $2 A$, military spouses will receive lower hiring recommendations than comparable civilian spouse, is also rejected. After 
controlling for applicant characteristics, hiring-based assessments, and respondent demographics, military spouses experience a premium - they receive a higher hiring recommendation compared to civilian spouse peers. Finally, Hypothesis 3A, military spouses with a history of frequent moving will receive higher hiring recommendations than comparable civilian spouses with a history of frequent moving is rejected. Military spouses and civilian spouses with a history of geographic stability experience similar hiring recommendation penalties after controlling for applicant characteristics, hiring-based assessments, and respondent demographics.

Finally, the second outcome of interest is starting salary offer. Hypothesis $1 B$, applicants with a history of frequent moving (tied migrants) will receiver lower salary offers than applicants with a history of geographic stability, is rejected. After controlling for applicant characteristics, hiring-based assessments, and respondent demographics, those with a history of frequent moving do not receive a lower salary offer. Hypothesis $2 B$, military spouses will receive a lower salary offer than comparable civilian spouses, is also rejected, as military spouses do not receive a lower salary offer than comparable civilian spouses after controlling for applicant characteristics, hiring-based assessments, and respondent demographics. Finally, Hypothesis $3 B$ stated military spouses with a history of frequent moving (tied migrants) will receive higher salary offers than comparable civilian spouses with a history of frequent moving. This hypothesis is rejected, as there were not statistically significant disparate salary offers between these two groups after controlling for applicant characteristics, hiring-based assessments, and respondent demographics. 


\section{DISCUSSION \& CONCLUSION}

This article presents results from an original factorial vignette survey which examined how tied migration - frequent moving - influenced the evaluations of fictitious job applicants. Several key findings emerge from these results. One, regardless of whether military spouses have actually moved frequently in the past or not, they are rated lower than comparable civilian spouses on anticipated longevity, or job tenure, with a company. This interim hiring-based assessment by employers influences the overall likelihood that an applicant will be recommended to hire. Secondly, military spouses with a stable geographic history are evaluated higher than civilians, but that premium switches to a penalty for military spouses with a history of moving frequently, in which case they are evaluated more harshly than civilians who have moved frequently.

This shows hiring decision makers are critical of job candidates with a history of frequent moving, and military spouses may be more likely to have an interrupted work history due to being married to someone in the military. Finally, there are no statistically significant differences in the starting salary offer between applicants who moved frequently and applicants who have been geographically stable, nor between military and civilian spouses with comparable characteristics. It is possible that frequent moving, signaling a pattern of tied migration, is not the most salient feature to hiring decision makers when determining a starting salary. These findings lead to a critical inquiry: perhaps the employment penalty military spouses experience is not due to being a military spouse per se, but due to the signal of a military spouse indicating future frequent moving. This remains a ripe area for further research; future studies should control for an indicator of future mobility to disentangle whether the signal of future mobility is the primary origin of a military spouse penalty. 
While not necessarily contradicting previous studies establishing a military spouse employment penalty (e.g. Bradbard et al. 2016; Hisnanick and Little 2015), these results suggest the need for a deeper dive into the underlying mechanisms resulting in military spouses having worse employment outcomes. The employment of military spouses is a priority for the military (United States 2012), and understanding how military spouses get jobs is essential to addressing current employment gaps among this population. In many ways, military spouses' ability to secure employment may be a proxy for their overall satisfaction. Spousal satisfaction is a key determinant of military retention, making this topic an important priority for the military (Bourg and Segal 1999). Recognizing the labor market penalties of being a military spouse, the military has developed military-spouse specific employment programs, but these initiatives may have limited effectiveness (United States Government Accountability Office 2012).

This study is not without limitations. The research design did not include race/ethnicity or branch and rank of the enlisted service member in the fictitious applicant profiles. These dimensions may influence how applicants are evaluated and are ripe opportunities for future research. Additionally, while all analyses were limited to those with hiring experience, it is possible that the respondents in this sample do not accurately reflect how employers evaluate job applicants. Despite these limitations, the findings make three primary contributions to military studies and the sociology of work. First, the results suggest a military spouse premium in terms of hiring-based assessments (warmth, competence, reliability, and sociability), which provides an important launching off point for future studies. Secondly, there is a penalty for frequent moving, which contributes to better understanding the specific mechanisms that lead to the under- and unemployment of military spouses. Finally, the results can be extended to other tied migrants, which are increasingly part of our new economy. 
While this project has important implications for military spouses, there are many professions that require employees to move in order to maintain or seek career promotions. For instance, academics, corporate executives, athletes/entertainers, and health care professionals all may have to move to complete their training and to advance their careers. Many of these employees have partners or families, and their educational and career trajectories are subsequently interrupted. Understanding how tied migrants may be evaluated based on their interrupted work history due to frequent moving is relevant to many careers outside of the military, and will likely be increasingly common as the "knowledge economy" and changing nature of work continue to evolve. 


\section{References}

Benson, Alan. 2014. "Rethinking the Two-Body Problem: The Segregation of Women Into Geographically Dispersed Occupations.” Demography 51(5):1619-39.

Bills, David B. 1990. “Employers’ Use of Job History Data for Making Hiring Decisions: A Fuller Specification of Job Assignment and Status Attainment.” The Sociological Quarterly 31(1):23-35.

Booth, Bradford. 2003. “Contextual Effects of Military Presence on Women's Earnings.” Armed Forces \& Society 30(1):25-51.

Bourg, Chris and Mady Wechsler Segal. 1999. "The Impact of Family Supportive Policies and Practices on Organizational Commitment to the Army." Armed Forces \& Society 25(4):633-52.

Bradbard, Deborah A., Rosalinda Maury, and Nicholas J. Armstrong. 2016. "The Force Behind the Force: A Business Case for Leveraging Military Spouse Talent.” Institute for Veterans and Military Families (July).

Bureau of Labor Statistics. 2016. Persons at Work by Occuation, Sex, and Ususal Full-or PartTime Status. Washington, D.C. Retrieved (https://www.bls.gov/cps/cpsaat23.pdf).

Castaneda, L. W. and M. C. Harrell. 2007. "Military Spouse Employment: A Grounded Theory Approach to Experiences and Perceptions.” Armed Forces \& Society 34(3):389-412.

Cooke, Thomas J. 2013. “All Tied Up: Tied Staying and Tied Migration within the United States, 1997 to 2007.” Demographic Research 29(October):817-36. Retrieved (http://0www.demographicresearch.org.library.unl.edu/volumes/vol29/30/\%5Cnhttp://www.demographicresearch.org/volumes/vol29/30/). 
Cooke, Thomas J. and Karen Speirs. 2005. "Migration and Employment Among the Civilian Spouses of Military Personnel.” Social Science Quarterly 86(2):343-55.

Cooney, Richard, Karin De Angelis, and Mady Wechsler Segal. 2011. "Moving with the Military: Race, Class, and Gender Differences in the Employment Consequences of Tied Migration." Race, Gender \& Class 18(1):360-84.

Correll, Shelley J., Stephen Benard, and In Paik. 2007. "Getting a Job: Is There a Motherhood Penalty?” American Journal of Sociology 112(5):1297-1339.

Cuddy, Amy J. C., Susan T. Fiske, and Peter Glick. 2008. "Warmth and Competence as Universal Dimensions of Social Perception: The Stereotype Content Model and the BIAS Map." Advances in Experimental Social Psychology 40(7):61-149.

Gaddis, Michael S. 2015. "Discrimination in the Credential Society: An Audit Study of Race and College Selectivity in the Labor Market.” Social Forces 93(4):1451-59.

Gates, Gary J. 2011. How Many People Are Lesbian, Gay, Bisexual, and Transgender? Retrieved (https://williamsinstitute.law.ucla.edu/wp-content/uploads/Gates-How-ManyPeople-LGBT-Apr-2011.pdf).

Gordon, Rachel A. 2010. Regression Analysis for the Social Sciences. 2nd ed. New York: Routledge.

Grilli, Leonardo and Carla Rampichini. 2005. A Review of Random Effects Modelling Using Gllamm in Stata. Florence, Italy. Retrieved (http://www.bristol.ac.uk/cmm/learning/mmsoftware/reviewgllamm.pdf).

Harrell, M. C., Nelson Lim, L. W. Castaneda, and Daniela Golinelli. 2004. "Working Around the Military: Challenges to Military Spouse Employment and Education.” RAND: National Defense Research Institute. Retrieved 
(http://www.rand.org/content/dam/rand/pubs/monographs/2005/RAND_MG341.pdf).

Hisnanick, J. J. and Roger D. Little. 2015. “'Honey, I Love You, but...' Investigating the Causes of the Earnings Penalty of Being A Tied-Migrant Military Spouse.” Armed Forces \& Society 41(3):413-39.

Hosek, J. and S. M. Wadsworth. 2013. "Economic Conditions of Military Families.” The Future of Children 23(2):41-59.

Hox, Joop J., Ita G. Kreft, and Piet L. Hermkens. 1991. "The Analysis of Factorial Surveys.” Sociological Methods \& Research 19(4):493-510.

Jasso, G. 2006. "Factorial Survey Methods for Studying Beliefs and Judgments." Sociological Methods \& Research 34(3):334-423.

Jones Young, Nicole C. and Gary N. Powell. 2015. "Hiring Ex-Offenders: A Theoretical Model." Human Resource Management Review 25(3):298-312. Retrieved (http://dx.doi.org/10.1016/j.hrmr.2014.11.001).

Krings, Franciska, Sabine Sczesny, and Annette Kluge. 2011. "Stereotypical Inferences as Mediators of Age Discrimination: The Role of Competence and Warmth." British Journal of Management 22:187-201.

Lakhani, Hyder. 1994. "The Socioeconomic Benefits to Military Families of Home-Basing of Armed Forces." Armed Forces \& Society 21(1):113-28.

Mincer, Jacob. 1978. “Family Migration Decisions.” Journal of Political Economy 86(5):749_ 73.

Mishel, Emma. 2016. "Discrimination against Queer Women in the U.S. Workforce: A Résumé Audit Study.” Socius: Sociological Research for a Dynamic World 2.

Park, Edward J. W. 1999. "Racial Ideology and Hiring Decisions in Silicon Valley." Qualitative 
Sociology 22(3):223-33.

Payne, Deborah M., John T. Warner, and Roger D. Little. 1992. "Tied Migration and Military Wives' Returns to Human Capital: The Case of Military Wives.” Social Science Quarterly 73(2):324-39.

Pedulla, David S. 2014. “The Positive Consequences of Negative Stereotypes: Race, Sexual Orientation, and the Job Application Process.” Social Psychology Quarterly 77(1):75-94.

Pedulla, David S. 2016. "Penalized or Protected? Gender and the Consequences of Non-Standard and Mismatched Employment Histories.” American Sociological Review 81(2):262-89.

Pew Research Center. 2011. The Military-Civilian Gap: Fewer Family Connections. Washington, D.C. Retrieved (http://www.pewsocialtrends.org/2011/11/23/the-militarycivilian-gap-fewer-family-connections/).

Rivera, Lauren A. 2012. "Hiring as Cultural Matching: The Case of Elite Professional Service Firms.” American Sociological Review 77(6):999-1022.

Rossi, Peter Henry and Steven L. Nock. 1982. Measuring Social Judgments: The Factorial Survey Approach. New York: Sage Publications.

Schwartz, J.Brad, Lisa L. Wood, and Janet D. Griffith. 1991. "The Impact of Military Life on Spouse Labor Force Outcomes." Armed Forces \& Society 17(3):385-407.

Segal, Mady Wechsler. 1986. "The Military and the Family as Greedy Institutions.” Armed Forces \& Society 13:9-38.

Shauman, Kimberlee A. and Mary C. Noonan. 2007. "Family Migration and Labor Force Outcomes: Sex Differences in Occupational Context.” Social Forces 85(4):1735-64. Taylor, Paul, Rich Morin, D’Vera Cohn, and Wendy Wang. 2008. American Mobility: Who Moves? Who Stays Put? Where's Home? Retrieved 
(http://www.pewsocialtrends.org/2008/12/17/who-moves-who-stays-put-wheres-home/).

The Williams Institute. 2016. Same-Sex Couples and LGBT Demographic Data. Los Angeles.

Retrieved (http://williamsinstitute.law.ucla.edu/visualization/lgbtstats/?topic=LGBT\&compare=percentage\#comparison).

Tilcsik, András. 2011. "Pride and Prejudice: Employment Discrimination against Openly Gay Men in the United States 1." American Journal of Sociology 117(2):586-626.

United States Census Bureau. 2010. 2010 Demographic Profile Data. Retrieved (https://factfinder.census.gov/faces/tableservices/jsf/pages/productview.xhtml?pid=DEC_10 _DP_DPDP1\&src=pt).

United States Government Accountability Office. 2012. "Military Spouse Employment Programs." United States Government Accountability Office (December).

Wallander, Lisa. 2009. "25 Years of Factorial Surveys in Sociology: A Review." Social Science Research 38(3):505-20. Retrieved (http://dx.doi.org/10.1016/j.ssresearch.2009.03.004).

Weinberg, Jill, Jeremy Freese, and David McElhattan. 2014. “Comparing Data Characteristics and Results of an Online Factorial Survey between a Population-Based and a CrowdsourceRecruited Sample.” Sociological Science 1(August):292-310.

Wong, Jaclyn S. 2017. “Competing Desires: How Young Adult Couples Negotiate Moving for Career Opportunities." Gender \& Society 31(2):171-96. 


\section{APPENDIX A}

\section{Sample Vignette}

This applicant is a woman who has applied for the Human Resources Assistant position at your consulting

firm, Forward Strategy, Inc. She recently moved to the area because her husband is on active duty in the military and has been stationed at a nearby military installation. Her resume indicates that she has a Bachelor's degree and her most recent experience is working full-time as an hourly employee as a receptionist at a local non-profit organization. It seems that this past job underutilized her skills and experience. Prior to moving to this area, she had 3 jobs in the last 5 years, apparently due to relocation. This applicant has one child. She noted on her application that she is eager to meet people and become familiar with the area.

\section{Rating Task Questions}

1. Compared to your other co-workers, how likeable do you think this applicant would be? [warmth]

2. How likely would this applicant be to complete tasks correctly and to meet deadlines without needing reminders? [competence]

3. How likely is it that this applicant would arrive late or leave early several times within a month? [reliability; this variable was reverse coded for analysis]

4. How likely would you be to have a friendship with this person outside of work? [sociability/network]

5. How likely is it that this applicant will stay with the company for 3 or more years? [longevity]

6. How likely would you be to hire this applicant? [overall assessment]

7. The typical starting salary for this position is between $\$ 25,000-\$ 45,000$. In the event that you end up hiring this applicant, what would you offer her as a starting salary?
○ \$25,000-\$29,999
○ $\$ 30,000-\$ 34,999$
○ $\$ 35,000-\$ 39,999$
○ $40,000-\$ 44,999$ 
Move the slider to the place on the scale that best fits your first impression of this applicant. Responses at the midpoint will only be recorded if you click the slider.

Not at all Likely/Likeable

1

2

3

How likely is it that this applicant will stay with the company for 3 or more years?

How likely would this applicant be to complete tasks correctly and to meet deadlines without needing reminders?

How likely would you be to have a friendship with this person outside of work?

Compared to your other co-workers, how likeable do you think this applicant would be?

How likely is it that this applicant would arrive late or leave early several times within a month?

How likely would you be to hire this applicant?
Extremely Likely/Likeable

6

7 
APPENDIX B: Replicated analyses on full sample $(N=662)$.

Table 2f. Difference of Means for Hiring Outcome by Applicant Characteristics

\begin{tabular}{|c|c|c|c|c|c|}
\hline \multirow{4}{*}{$\begin{array}{l}\text { Sexual Orientation } \\
\text { Sello }\end{array}$} & \multicolumn{3}{|c|}{ Military or Civilian Spouse } & \multirow{3}{*}{\multicolumn{2}{|c|}{$\begin{array}{c}\text { Total } \\
\text { Hire }\end{array}$}} \\
\hline & \multirow{2}{*}{$\begin{array}{r}\text { Civilian } \\
\text { Hire }\end{array}$} & \multirow{2}{*}{\multicolumn{2}{|c|}{$\begin{array}{r}\text { Military } \\
\text { Hire }\end{array}$}} & & \\
\hline & & & & & \\
\hline & & & & & \\
\hline Straight & 4.28 & 4.23 & & 4.26 & \\
\hline Lesbian & 4.24 & 4.25 & & 4.24 & \\
\hline Total & 4.26 & 4.24 & & 4.25 & \\
\hline \multicolumn{6}{|l|}{ Education } \\
\hline High School Diploma & 4.02 & 4.01 & & 4.01 & \\
\hline Bachelor's & 4.50 & 4.47 & & 4.49 & \\
\hline Total & 4.26 & 4.24 & & 4.25 & $* *$ \\
\hline \multicolumn{6}{|l|}{ Previous Work Experience } \\
\hline Full Time & 4.38 & 4.32 & & 4.35 & \\
\hline Part Time & 4.15 & 4.22 & & 4.19 & \\
\hline Volunteer & 4.25 & 4.18 & & 4.22 & \\
\hline Total & 4.26 & 4.24 & & 4.25 & $* *$ \\
\hline \multicolumn{6}{|l|}{ Skill Utilization } \\
\hline Skills underutilized & 4.28 & 4.26 & & 4.27 & \\
\hline Skills utilized & 4.23 & 4.22 & & 4.23 & \\
\hline Total & 4.26 & 4.24 & & 4.25 & \\
\hline \multicolumn{6}{|l|}{ Parent } \\
\hline No & 4.33 & 4.32 & & 4.33 & \\
\hline Yes & 4.19 & 4.16 & & 4.17 & \\
\hline Total & 4.26 & 4.24 & & 4.25 & $* *$ \\
\hline \multicolumn{6}{|c|}{ History of Geographic Mobility } \\
\hline Geographically stable & 4.87 & 4.77 & $*$ & 4.82 & \\
\hline Moved frequently & 3.64 & 3.71 & & 3.67 & \\
\hline Total & 4.26 & 4.24 & & 4.25 & $* *$ \\
\hline
\end{tabular}


Table 3f. Difference of Means for Hiring Outcome by Applicant Characteristics

\begin{tabular}{|c|c|c|c|c|c|c|}
\hline \multicolumn{7}{|c|}{$\begin{array}{c}\text { Interaction of Military Spouse Status \& } \\
\text { Geographic Mobility }\end{array}$} \\
\hline & Civ-Stable & Mil-Stable & Civ-Mobile & Mil-Mobile & \multirow{2}{*}{\multicolumn{2}{|c|}{$\begin{array}{c}\text { Total } \\
\text { Hire }\end{array}$}} \\
\hline & Hire & Hire & Hire & Hire & & \\
\hline \multicolumn{7}{|l|}{ Sexual Orientation } \\
\hline Straight & 4.86 & 4.76 & 3.69 & 3.71 & 4.26 & \\
\hline Lesbian & 4.88 & 4.78 & 3.59 & 3.70 & 4.24 & \\
\hline Total & 4.87 & 4.77 & 3.64 & 3.71 & 4.25 & \\
\hline \multicolumn{7}{|l|}{ Education } \\
\hline High School & 4.56 & 4.49 & 3.47 & 3.53 & 4.01 & \\
\hline Diploma & & & & & & \\
\hline Bachelor's & 5.18 & 5.06 & 3.81 & 3.89 & 4.49 & \\
\hline Total & 4.87 & 4.77 & 3.64 & 3.71 & 4.25 & $* *$ \\
\hline \multicolumn{7}{|c|}{ Previous Work Experience } \\
\hline Full Time & 4.99 & 4.88 & 3.76 & 3.75 & 4.35 & \\
\hline Part Time & 4.77 & 4.74 & 3.53 & 3.72 & 4.19 & \\
\hline Volunteer & 4.86 & 4.69 & 3.64 & 3.66 & 4.22 & \\
\hline Total & 4.87 & 4.77 & 3.64 & 3.71 & 4.25 & $* *$ \\
\hline \multicolumn{7}{|l|}{ Skill Utilization } \\
\hline Skills underutilized & 4.88 & 4.81 & 3.69 & 3.71 & 4.27 & \\
\hline Skills utilized & 4.87 & 4.73 & 3.60 & 3.70 & 4.23 & \\
\hline Total & 4.87 & 4.77 & 3.64 & 3.71 & 4.25 & \\
\hline \multicolumn{7}{|l|}{ Parent } \\
\hline No & 4.95 & 4.90 & 3.71 & 3.74 & 4.33 & \\
\hline Yes & 4.80 & 4.64 & 3.57 & 3.67 & 4.17 & \\
\hline Total & 4.87 & 4.77 & 3.64 & 3.71 & 4.25 & $* *$ \\
\hline
\end{tabular}

Note: Mean hiring scores are presented; applicants were rated on a scale of 1 (low) to 7 (high).

$* \mathrm{p}<.05 * * \mathrm{p}<.01$ (ANOVA test with bonferroni adjustment comparing civ/mil stable and civ/mil mobile). There are no statistically significant differences between military and civilian spouses in either geographic mobility category. 
Table 4f. Difference of Means Hiring-Based Assessments

\begin{tabular}{lrrrrrrrrr}
\hline & \multicolumn{3}{c}{ History of Geographic Mobility } & & & \multicolumn{3}{c}{ Military or Civ Spouse } & \\
\cline { 2 - 3 } & Geo Stable & Moved Freq & Total & Civilian & Military & Total \\
\hline Warmth & 4.91 & 4.63 & $* *$ & 4.77 & 4.74 & 4.80 & $*$ & 4.77 \\
Competence & 5.24 & 4.84 & $* *$ & 5.04 & & 5.00 & 5.09 & $* *$ & 5.04 \\
Reliability & 4.90 & 4.45 & $* *$ & 4.68 & & 4.63 & 4.72 & $* *$ & 4.68 \\
Sociability & 4.33 & 4.01 & $* *$ & 4.17 & & 4.12 & 4.22 & $* *$ & 4.17 \\
Longevity & 5.05 & 2.69 & $* *$ & 3.88 & & 4.09 & 3.66 & $* *$ & 3.88
\end{tabular}

Note: Mean assessment scores are presented; applicants were rated on a scale of 1 (low) to 7 (high).

$* \mathrm{p}<.05 * * \mathrm{p}<.01$ (two-tailed tests)

Table 5f. Difference of Means Hiring-Based Assessments, Interaction of Military Spouse Status \& Geographic Mobility

\begin{tabular}{|c|c|c|c|c|c|c|c|}
\hline & Civ-Stable & Mil-Stable & & Civ-Mobile & Mil-Mobile & & Total \\
\hline Warmth & 4.89 & 4.93 & & 4.59 & 4.67 & * & 4.77 \\
\hline Competence & 5.22 & 5.27 & & 4.77 & 4.91 & ** & 5.04 \\
\hline Reliability & 4.9 & 4.91 & & 4.36 & 4.53 & ** & 4.68 \\
\hline Sociability & 4.29 & 4.38 & * & 3.96 & 4.06 & * & 4.17 \\
\hline Longevity & 5.42 & 4.69 & ** & 2.76 & 2.61 & ** & 3.88 \\
\hline
\end{tabular}

Note: Mean assessment scores are presented; applicants were rated on a scale of 1 (low) to 7 (high).

$* \mathrm{p}<.05 * * \mathrm{p}<.01$ (two-tailed tests comparing civ/mil stable and civ/mil mobile separately). 
Table 6f. Hiring Recommendation, Mixed-Effects Multilevel Regression Models

\begin{tabular}{|c|c|c|c|c|c|c|c|c|c|c|}
\hline \multirow{2}{*}{ Vignette Characteristics } & \multicolumn{2}{|l|}{ Baseline } & \multicolumn{2}{|l|}{ M 1} & \multicolumn{2}{|l|}{ M 2} & \multicolumn{2}{|l|}{ M 3} & \multicolumn{2}{|l|}{ M 4} \\
\hline & & & & & & & & & & \\
\hline \multirow[t]{2}{*}{ Military Spouse (Civilian) } & -0.05 & & -0.14 & $* * *$ & -0.13 & $* * *$ & 0.08 & $* *$ & 0.08 & $* *$ \\
\hline & $(0.03)$ & & $(0.04)$ & & $(0.04)$ & & $(0.03)$ & & $(0.03)$ & \\
\hline \multirow[t]{2}{*}{ Geo Mobile (Stable) } & -1.16 & $* * *$ & -1.25 & $* * *$ & -1.25 & $* * *$ & -0.13 & $* * *$ & -0.13 & $* * *$ \\
\hline & $(0.03)$ & & $(0.04)$ & & $(0.04)$ & & $(0.04)$ & & $(0.04)$ & \\
\hline \multicolumn{11}{|c|}{ Mil Spouse x Geo Mobile (Civ x Stable) } \\
\hline \multirow[t]{2}{*}{ Civilian Spouse x Moved Freq } & & & -1.25 & $* * *$ & -1.25 & $* * *$ & -0.13 & $* * *$ & -0.13 & $* * *$ \\
\hline & & & $(0.04)$ & & $(0.04)$ & & $(0.04)$ & & $(0.04)$ & \\
\hline \multirow[t]{2}{*}{ Military Spouse x Geo Stable } & & & -0.14 & $* * *$ & -0.13 & $* * *$ & 0.08 & $* *$ & 0.08 & $* *$ \\
\hline & & & $(0.04)$ & & $(0.04)$ & & $(0.03)$ & & $(0.03)$ & \\
\hline \multirow[t]{2}{*}{ Military Spouse x Moved Freq } & & & -1.20 & $* * *$ & -1.20 & $* * *$ & -0.13 & $* * *$ & -0.13 & $* * *$ \\
\hline & & & $(0.04)$ & & $(0.04)$ & & $(0.04)$ & & $(0.04)$ & \\
\hline \multirow[t]{2}{*}{ Bachelor's (High School) } & & & & & 0.54 & $* * *$ & 0.27 & $* * *$ & 0.27 & $* * *$ \\
\hline & & & & & $(0.03)$ & & $(0.02)$ & & $(0.02)$ & \\
\hline \multicolumn{11}{|l|}{ Previous Position (Full Time) } \\
\hline \multirow[t]{2}{*}{ Part-time } & & & & & -0.14 & $* * *$ & -0.07 & $* *$ & -0.07 & $* *$ \\
\hline & & & & & $(0.03)$ & & $(0.03)$ & & $(0.03)$ & \\
\hline \multirow[t]{2}{*}{ Volunteer } & & & & & -0.13 & $* * *$ & -0.09 & $* * *$ & -0.09 & $* * *$ \\
\hline & & & & & $(0.03)$ & & $(0.03)$ & & $(0.02)$ & \\
\hline \multirow[t]{2}{*}{ Skills utilized (Not Utilized) } & & & & & -0.05 & & -0.06 & $* *$ & -0.05 & $* *$ \\
\hline & & & & & $(0.03)$ & & $(0.02)$ & & $(0.02)$ & \\
\hline \multirow[t]{2}{*}{ Parent (No Children) } & & & & & -0.16 & $* * *$ & -0.04 & & -0.04 & \\
\hline & & & & & $(0.03)$ & & $(0.02)$ & & $(0.02)$ & \\
\hline \multicolumn{11}{|l|}{ Hiring Based Assessments } \\
\hline \multirow[t]{2}{*}{ Warmth } & & & & & & & 0.16 & $* * *$ & 0.16 & $* * *$ \\
\hline & & & & & & & $(0.02)$ & & $(0.02)$ & \\
\hline \multirow[t]{2}{*}{ Competence } & & & & & & & 0.33 & $* * *$ & 0.33 & $* * *$ \\
\hline & & & & & & & $(0.01)$ & & $(0.01)$ & \\
\hline \multirow[t]{2}{*}{ Reliability } & & & & & & & 0.08 & $* * *$ & 0.08 & $* * *$ \\
\hline & & & & & & & $(0.01)$ & & $(0.01)$ & \\
\hline \multirow[t]{2}{*}{ Sociability } & & & & & & & 0.16 & $* * *$ & 0.16 & $* * *$ \\
\hline & & & & & & & $(0.01)$ & & $(0.01)$ & \\
\hline \multirow[t]{2}{*}{ Longevity } & & & & & & & 0.30 & $* * *$ & 0.30 & $* * *$ \\
\hline & & & & & & & $(0.01)$ & & $(0.01)$ & \\
\hline Constant & 4.85 & $* * *$ & 4.89 & $* * *$ & 4.82 & $* * *$ & -0.40 & $* * *$ & 0.16 & \\
\hline & $(0.04)$ & & $(0.04)$ & & $(0.05)$ & & $(0.1)$ & & $(0.2)$ & \\
\hline Respondent Variance & -0.23 & $* * *$ & -0.23 & $* * *$ & -0.21 & $* * *$ & -0.56 & $* * *$ & -0.60 & $* * *$ \\
\hline & $(0.03)$ & & $(0.03)$ & & $(0.03)$ & & $(0.03)$ & & $(0.03)$ & \\
\hline
\end{tabular}




\begin{tabular}{|c|c|c|c|c|c|c|c|c|c|}
\hline Vignette Variance & $\begin{array}{r}0.05 \\
(0.01)\end{array}$ & $* * *$ & $\begin{array}{r}0.05 \\
(0.01)\end{array}$ & $* * *$ & $\begin{array}{r}0.01 \\
(0.01)\end{array}$ & & $\begin{array}{c}-0.23 \\
(0.01)\end{array}$ & $* * *$ & $\begin{array}{r}-0.23 \\
(0.01)\end{array}$ \\
\hline -2 log-likelihood & $-10,000$ & & 10,000 & & 10,000 & & $-8,501$ & & $-8,477$ \\
\hline Chi-square & 2,491 & $* * *$ & 8,226 & $* * *$ & 8,226 & $* * *$ & 8,323 & $* * *$ & 8,323 \\
\hline $\mathrm{N}$ & 6,619 & & 6,619 & & 6,619 & & 6,619 & & 6,619 \\
\hline
\end{tabular}

Note: Reference groups and standard errors are in parentheses. Respondent demographics are included in Model 4 but are not shown here.

$* \mathrm{p}<.05 * * \mathrm{p}<.01 * * * \mathrm{p}<.001$ (two-tailed tests). 
Table 7f. Difference of Means for Salary Outcome by Applicant Characteristics

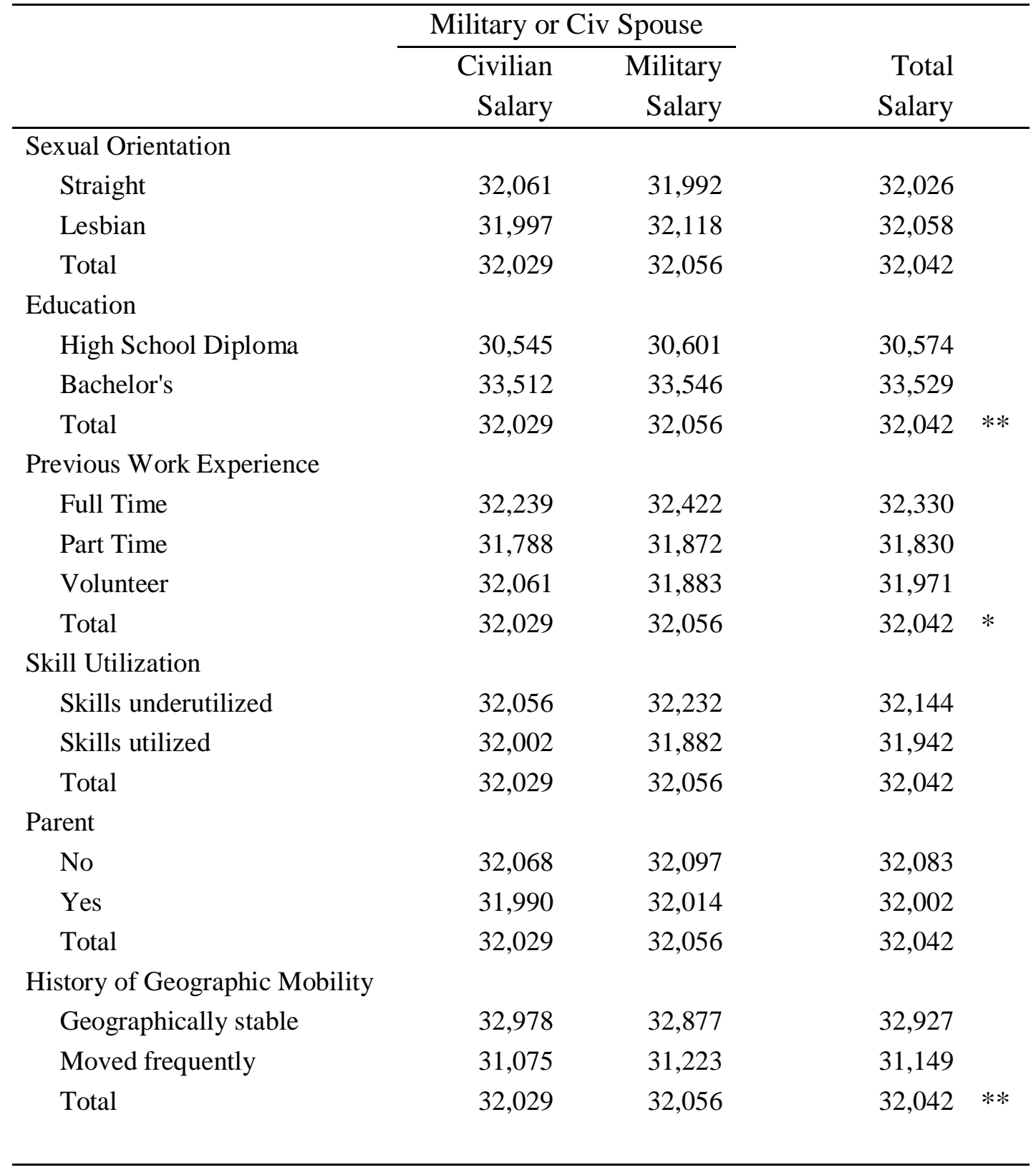

Note: Mean starting salary offers are presented. $* \mathrm{p}<.05 * * \mathrm{p}<.01$ (two-tailed tests).

There are no statistically significant differences between military and civilian spouses. 
Table 8f. Difference of Means for Salary Outcome by Applicant Characteristics

\begin{tabular}{|c|c|c|c|c|c|c|}
\hline & \multicolumn{4}{|c|}{$\begin{array}{c}\text { Interaction of Military Spouse Status \& } \\
\text { Geographic Mobility }\end{array}$} & \multirow{3}{*}{$\begin{array}{r}\text { Total } \\
\text { Salary }\end{array}$} & \\
\hline & Civ-Stable & Mil-Stable & Civ-Mobile & Mil-Mobile & & \\
\hline & Salary & Salary & Salary & Salary & & \\
\hline \multicolumn{7}{|l|}{ Sexual Orientation } \\
\hline Straight & 33,025 & 32,880 & 31,089 & 31,115 & 32,026 & \\
\hline Lesbian & 32,930 & 32,874 & 31,062 & 31,331 & 32,058 & \\
\hline Total & 32,978 & 32,877 & 31,075 & 31,223 & 32,042 & \\
\hline \multicolumn{7}{|l|}{ Education } \\
\hline High School & 31,217 & 31,315 & 29,879 & 29,867 & 30,574 & \\
\hline \multicolumn{7}{|l|}{ Diploma } \\
\hline Bachelor's & 34,718 & 34,502 & 32,286 & 32,591 & 33,529 & \\
\hline Total & 32,978 & 32,877 & 31,075 & 31,223 & 32,042 & $* *$ \\
\hline \multicolumn{7}{|c|}{ Previous Work Experience } \\
\hline Full Time & 33,239 & 33,411 & 31,232 & 31,413 & 32,330 & \\
\hline Part Time & 32,736 & 32,527 & 30,839 & 31,221 & 31,830 & \\
\hline Volunteer & 32,959 & 32,700 & 31,157 & 31,042 & 31,971 & \\
\hline Total & 32,978 & 32,877 & 31,075 & 31,223 & 32,042 & $*$ \\
\hline \multicolumn{7}{|l|}{ Skill Utilization } \\
\hline Skills underut. & 32,894 & 33,041 & 31,210 & 31,422 & 32,144 & \\
\hline Skills utilized & 33,061 & 32,718 & 30,942 & 31,025 & 31,942 & \\
\hline Total & 32,978 & 32,877 & 31,075 & 31,223 & 32,042 & \\
\hline \multicolumn{7}{|l|}{ Parent } \\
\hline No & 33,074 & 32,998 & 31,050 & 31,203 & 32,083 & \\
\hline Yes & 32,881 & 32,759 & 31,101 & 31,242 & 32,002 & \\
\hline Total & 32,978 & 32,877 & 31,075 & 31,223 & 32,042 & \\
\hline
\end{tabular}

Note: Mean starting salary offers are presented.

$* \mathrm{p}<.05 * * \mathrm{p}<.01$ (ANOVA test with bonferroni adjustment comparing civ/mil stable and civ/mil mobile).

There are no statistically significant differences between military and civilian spouses. 
Table 9f. Starting Salary, Mixed-Effects Multilevel Regression Models

\begin{tabular}{|c|c|c|c|c|c|c|c|c|c|c|}
\hline \multirow{2}{*}{ Vignette Characteristics } & \multicolumn{2}{|l|}{ Baseline } & \multicolumn{2}{|l|}{ M 1} & \multicolumn{2}{|l|}{ M 2} & \multicolumn{2}{|l|}{ M 3} & \multicolumn{2}{|l|}{ M 4} \\
\hline & & & & & & & & & & \\
\hline \multirow[t]{2}{*}{ Military Spouse (Civilian) } & 38 & & -86 & & -55 & & 274 & $* *$ & 268 & $* *$ \\
\hline & (86) & & $(121)$ & & (106) & & (97) & & (97) & \\
\hline \multirow[t]{2}{*}{ Geographically Mobile (Stable) } & $-1,850$ & $* * *$ & $-1,976$ & $* * *$ & $-1,954$ & $* * *$ & 78 & & 73 & \\
\hline & (86) & & (123) & & $(107)$ & & (122) & & $(122)$ & \\
\hline \multicolumn{11}{|c|}{ Mil Spouse x Geo Mobile (Civ x Stable) } \\
\hline \multirow[t]{2}{*}{ Civilian Spouse x Moved Freq } & & & $-1,976$ & $* * *$ & $-1,954$ & $* * *$ & 78 & & 73 & \\
\hline & & & (123) & & 107 & & (122) & & $(122)$ & \\
\hline \multirow[t]{2}{*}{ Military Spouse x Geo Stable } & & & -86 & & -55 & & 274 & $* *$ & 268 & $* *$ \\
\hline & & & $(121)$ & & (106) & & (97) & & (97) & \\
\hline \multirow[t]{2}{*}{ Military Spouse x Moved Freq } & & & $-1,811$ & $* * *$ & $-1,823$ & $* * *$ & 82 & & 67 & \\
\hline & & & $(122)$ & & $(106)$ & & (124) & & (124) & \\
\hline \multirow[t]{2}{*}{ Bachelor's (High School) } & & & & & 3,203 & $* * *$ & 2,599 & $* * *$ & 2,595 & $* * *$ \\
\hline & & & & & $(75)$ & & $(69)$ & & (69) & \\
\hline \multicolumn{11}{|l|}{ Previous Position (Full Time) } \\
\hline \multirow[t]{2}{*}{ Part-time } & & & & & -610 & $* * *$ & -454 & $* * *$ & -454 & $* * *$ \\
\hline & & & & & $(92)$ & & (83) & & (83) & \\
\hline \multirow[t]{2}{*}{ Volunteer } & & & & & -423 & $* * *$ & -343 & $* * *$ & -345 & $* * *$ \\
\hline & & & & & (92) & & (82) & & $(82)$ & \\
\hline \multirow[t]{2}{*}{ Skills utilized (Not Utilized) } & & & & & -189 & $*$ & -200 & $* *$ & -201 & $* *$ \\
\hline & & & & & (75) & & (67) & & (67) & \\
\hline \multirow[t]{2}{*}{ Parent (No Children) } & & & & & -158 & $*$ & 61 & & 59 & \\
\hline & & & & & (75) & & (73) & & (73) & \\
\hline \multicolumn{11}{|l|}{ Hiring-Based Assessments } \\
\hline \multirow[t]{2}{*}{ Warmth } & & & & & & & 370 & $* * *$ & 378 & $* * *$ \\
\hline & & & & & & & (54) & & (54) & \\
\hline \multirow[t]{2}{*}{ Competence } & & & & & & & 831 & $* * *$ & 842 & $* * *$ \\
\hline & & & & & & & (45) & & (45) & \\
\hline \multirow[t]{2}{*}{ Reliability } & & & & & & & 119 & $* * *$ & 119 & $* * *$ \\
\hline & & & & & & & (31) & & (31) & \\
\hline \multirow[t]{2}{*}{ Sociability } & & & & & & & 400 & $* * *$ & 396 & $* * *$ \\
\hline & & & & & & & (43) & & (43) & \\
\hline \multirow[t]{2}{*}{ Longevity } & & & & & & & 495 & $* * *$ & 490 & $* * *$ \\
\hline & & & & & & & (29) & & (29) & \\
\hline Constant & 32,944 & $* * *$ & 33,007 & $* * *$ & 31,925 & $* * *$ & 20,880 & $* * *$ & 23,099 & $* * *$ \\
\hline & (129) & & (136) & & (157) & & (333) & & $(829)$ & \\
\hline Respondent Variance & 7.91 & $* * *$ & 7.91 & $* * *$ & 7.94 & $* * *$ & 7.91 & $* * *$ & 7.85 & $* * *$ \\
\hline & $(0.03)$ & & $(0.03)$ & & $(0.03)$ & & $(0.03)$ & & $(0.03)$ & \\
\hline
\end{tabular}




Vignette Variance
-2 log-likelihood
Chi-Square
$\mathrm{N}$

$8.12 * * *$
$(0.01)$
$-64,000$
$458 * * *$
6,619

$\begin{array}{rr}8.12 & * * * \\ (0.01) & \\ - & \\ 64,000 & \\ 460 & * * * \\ 6,619 & \end{array}$

$\begin{array}{rr}7.98 & * * * \\ (0.01) & \\ - & \\ 63,000 & \\ 2,472 & * * * \\ 6,619 & \end{array}$

$\begin{array}{rrrr}7.87 & * * * & 7.87 & * * * \\ (0.01) & & (0.01) & \\ - & & - & \\ 62,000 & & 62,000 & \\ 4,683 & * * * & 4,769 & * * * \\ 6,619 & & 6,619 & \end{array}$

Note: Reference groups and standard errors are in parentheses. Respondent demographics are included in Model 4 but are not shown here.

$* \mathrm{p}<.05 * * \mathrm{p}<.01 * * * \mathrm{p}<.001$ (two-tailed tests). 